\title{
Active tilting-pad journal bearings supporting flexible rotors: Part I - The hybrid lubrication
}

Salazar, Jorge Andrés González; Santos, IImar

Published in:

Tribology International

Link to article, DOI:

10.1016/j.triboint.2016.11.018

Publication date:

2017

Document Version

Peer reviewed version

Link back to DTU Orbit

Citation (APA):

Salazar, J. A. G., \& Santos, I. (2017). Active tilting-pad journal bearings supporting flexible rotors: Part I - The hybrid lubrication. Tribology International, 107, 94-105. https://doi.org/10.1016/j.triboint.2016.11.018

\section{General rights}

Copyright and moral rights for the publications made accessible in the public portal are retained by the authors and/or other copyright owners and it is a condition of accessing publications that users recognise and abide by the legal requirements associated with these rights.

- Users may download and print one copy of any publication from the public portal for the purpose of private study or research.

- You may not further distribute the material or use it for any profit-making activity or commercial gain

- You may freely distribute the URL identifying the publication in the public portal

If you believe that this document breaches copyright please contact us providing details, and we will remove access to the work immediately and investigate your claim. 


\title{
Active Tilting-Pad Journal Bearings Supporting Flexible Rotors: Part I - The Hybrid Lubrication
}

\author{
Jorge G. Salazar ${ }^{\mathrm{a}, \mathrm{b}}$, Ilmar F. Santos ${ }^{\mathrm{a}, *}$ \\ ${ }^{a}$ Department of Mechanical Engineering, Technical University of Denmark, 2800 Kgs. \\ Lyngby, Denmark \\ ${ }^{b}$ Department of Mechanical Engineering, University of La Frontera, Temuco, Chile
}

\begin{abstract}
This is part I of a twofold paper series, of theoretical and experimental nature, presenting the design and implementation of model-based controllers meant for assisting the hybrid and developing the feedback-controlled lubrication regimes in active tilting-pad journal bearings (active TPJBs). In part I, the flexible rotoractive TPJB modelling is thoroughly covered by establishing the link between the mechanical and hydraulic systems for all regimes. The hybrid lubrication is herein covered in depth; from a control viewpoint, an integral controller to aid such a regime is designed using model-based standard tools. Results show slight improvement on the system dynamic performance by using the hybrid lubrication instead of the passive one. Further improvements are pursued with the active lubrication in part II.
\end{abstract}

Keywords: Active Tilting-Pad Journal Bearings, Adjustable Lubrication, Vibration Suppression, Rotordynamics

\section{Introduction}

The fast development of the mechatronics has allowed a variety of machine elements to be upgraded. Among bearings, active magnetic [1, 2], gas (compressible) [3, 4, 5] and oil-film (uncompressible) bearings [6, 7] can be recognized. Within oil-film bearings, the development has focused on active tilting-pad journal bearings (active TPJBs) because it is an intrinsically

\footnotetext{
*Corresponding author

Email addresses: jgsal@mek.dtu.dk (Jorge G. Salazar), ifs@mek.dtu.dk (Ilmar F. Santos)
} 
stable bearing [8, 9] so it can safely run under demanding operational conditions with or without the active feature. Under a mechatronic approach, sensing and actuating capabilities are incorporated into the active bearing design. Suitable actuators for TPJBs are of a hydraulic nature [10], although magnetic or piezoelectric [11, 12] can also be implemented. In 1994, Santos [13] compared two types of hydraulic actuators for turning the conventional TPJBs into "active TPJBs", the chamber and the oil radial injection systems, with the last one as the most appropriated choice [14]. By injecting high pressurized oil through orifices, commonly only one centrally machined at the pad surface, three lubrication regimes can be developed due to the combination of the hydrostatic with the hydrodynamic principles: the conventional (pure hydrodynamic), the hybrid (hydrodynamic plus hydrostatic) and the controllable (hydrodynamic plus variable hydrostatic). In Santos and Russo [15, the isothermal modelling of active TPJBs featuring the radial oil injection system was firstly introduced. Since then, a great amount of research has been carried out mainly in two fundamental branches. The first one involves the modelling of active TPJBs, and the second focuses on the control design for such bearings. When modelling the active TPJBs, all considerations of an elastotherhydrodynamic (ETHD) approach are maintained including also the radial oil injection, hydraulic and pipelines dynamics among the relevant effects. A detailed development of the modelling on active TPJBs can be found in [16, 17, 18, 19]. On the other branch, the advances in the field of control design for active TPJBs have been deeply subjugated to the availability of accurate and reliable bearing models. Without such models to precisely predict the bearing properties, the integration of both areas for developing model-based controllers is limited. This limitation has circumscribed the control design to mainly classical PID controllers either via previous experimental system characterization or in-situ tuning. The actual maturity of the active TPJBs modelling, which allows us to comprehend the physics behind it, can lead to designing model-based controllers at an early stage of the bearing design. This avoids calculating the PID parameters by heuristic means or by tuning them on site after the bearing is manufactured. Works related to control design for active TPJBs can be found in [20, 21, 22, 23, 24, 25, 26].

In the industry, the majority of the critical machines feature flexible rotors which make them worth analysing when supported by active TPJBs, in the same way as when they are supported by conventional TPJBs [27, 28, 29, 30, 31, 32. In rotating systems, the bearing dynamic properties heavily influence 
the whole system dynamics because they provide the main source of energy dissipation through the lubricating fluid film. Besides the damping reduction with the increased angular velocity, this property also reduces with the excitation frequency, which indeed lowers the damping ratio of the flexible system modes. In this case, the design of model-based controllers for governing the active TPJBs becomes even more relevant and challenging for increasing the damping of such modes, provided proper actuators are available. Only a few publications, such as [24, 22, 33], deal with the targeted systems from a theoretical and experimental perspective simultaneously. Contrarily, rigid rotor systems are more profusely covered [13, 14, 34, 23, 20, 21].

In this framework, the main contribution of this work is fundamentally theoretical by presenting the modelling of flexible rotors when supported by active TPJBs. This modelling is based on the standard beam finite element formulation for the rotor and by including the full bearing matrices derived from an ETHD approach for the active TPJBs. This further includes the pad degrees-of-freedom (dofs) - tilt, bending and radial movement - and an extra dof - the servovalve spool-driven flow - which makes the link between the mechanical and hydraulic systems. Special emphasis is given to the modelling of the different lubrication regimes by analysing the influence of the fluid-film forces on the journal equilibrium and the bearing dynamic properties, leading to appropriated models for the passive, hybrid and active lubrication regimes. These models can be used for assisting the journal position changes under the hybrid lubrication regime or for designing model-based state-feedback controllers to develop the active lubrication, as presented next in part II. In this part, the hybrid lubrication is thoroughly covered and an integral controller derived using model-based tools is used to aid the journal equilibrium position changes. This study on flexible rotor-active bearing systems offers a more complete analysis that includes the flexible rotor dynamics and also serves to supplement the shortage identified previously.

\section{The Test Rig Facilities}

The rotor-bearing test rig, shown in Figure 1(a), resembles an industrial overhung centrifugal compressor. The driven torque is delivered through a flexible coupling connected to a layshaft, which is belt-driven by an AC motor. The rotor is supported by a ball and an active TPJB at the driven and free end respectively. Discs can be overhung at the shaft free end to resemble impellers and to increase the gyroscopic effect. None, one and up 


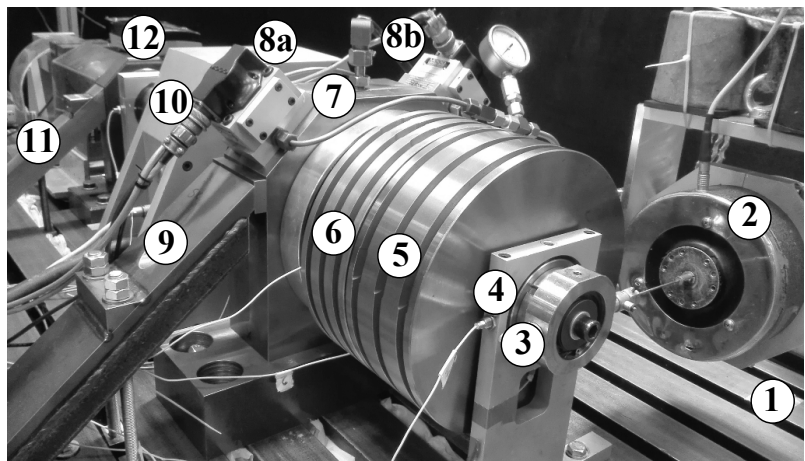

(a)

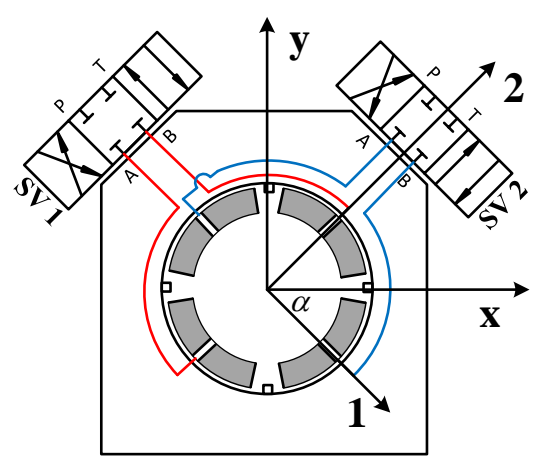

(b)

Figure 1: (a) Flexible rotor-actively lubricated TPJB test rig. (1) Metal t-slot foundation. (2) Electromagnetic shaker. (3) Excitation ball bearing. (4) Pedestal for sensors 1 (Horizontal) and 2 (Vertical). (5) Disc $100 \mathrm{~mm}$. (6) Disc $80 \mathrm{~mm}$. (7) Actively-lubricated TPJB. (8) Servovalves. (9) TPJB housing stiffener. (10) Magnetic exciter. (11) Ball bearing housing stiffener. (12) AC motor drive. (b) Active TPJB scheme and reference systems.

to two discs can be suspended. Without discs the rotor behaves as a rigid rotor at frequencies below $150 \mathrm{~Hz}$, whereas any extra disc means analysing it as a flexible one. The system can be excited either through an electromagnetic shaker connected to the excitation bearing at the shaft end or through the active magnetic bearing placed between bearings. The main design and operational characteristics of the test rig are summarized in Table 1.

\subsection{The Active TPJB and Lubrication Regimes}

The controllable bearing, schematized in Figure 1(b), is a tilting-pad journal bearing with 4 bronze pads in a load-between-pads configuration. The pad is centrally pivoted with a rocker type pivot. The active or controllable feature of the bearing is rendered by an electronic radial oil injection

Table 1: Test rig main design and operational characteristics.

\begin{tabular}{lccccccc}
\hline Property & Value & Unit & & Property & Value & Unit \\
\cline { 1 - 4 } \cline { 5 - 7 } AC motor power & 3 & $\mathrm{~kW}$ & & Bearing load / no disc & 400 & $\mathrm{~N}$ \\
Rotor max. speed & 7000 & $\mathrm{rpm}$ & & Bearing load / one disc (80 mm) & 880 & $\mathrm{~N}$ \\
Shaft length & 1150 & $\mathrm{~mm}$ & & Bearing load / two discs & 1440 & $\mathrm{~N}$ \\
Shaft weight & 49.5 & $\mathrm{~kg}$ & & Lubricant & ISO VG22 & - \\
Disc $80 \mathrm{~mm}$ weight & 37.3 & $\mathrm{~kg}$ & & Oil Viscosity & $1.892 \cdot 10^{-2}$ & $\mathrm{~kg} / \mathrm{ms}$ \\
Disc 100 mm weight & 46.0 & $\mathrm{~kg}$ & & Oil flow $(2$ bar $)$ & 1.3 & $\mathrm{~L} / \mathrm{min}$ \\
\hline
\end{tabular}


system as proposed by Santos [15]. This injection system combines a hydrostatic with the hydrodynamic pressure distribution by injecting pressurized oil in the journal-pad clearance through, in this case, a single centred nozzle aligned with the pivot lin $\AA^{1}$. The high pressure oil flow is injected by two high-frequency response servovalves, where each one couples to a pairwise of counter pads. Such pad sets are orthogonally installed. This servovalve-pad configuration enables us to freely exert controllable forces within the bearing plane so that any external force, such as imbalance, can be counteracted. One of the main components of the servovalve is the spool, whose position is driven by an input control signal which if set to positive, connects the supply port with one pad or if set to negative with the counter pad. With a zero input control signal, the servovalve's spool is centred to keep both ports closed, hence blocking the flow to the pads. However, due to tight fabrication tolerances between spool lands and ports being difficult to produce, the spool lands underlap the ports and a small leakage flow is always injected [39]. Further design parameters are presented in Table 2.

Figure 2 depicts the layout of the hydraulic units connected to the active TPJB. This includes a flooding system for the conventional lubrication and the electronic radial oil injection system for developing the hybrid and active lubrication when enabled. These regimes, which are mathematically approached in the next section, can be further described as follows:

The Passive Lubrication Regime: provides the main bearing dynamic properties and its load carrying capacity due to the hydrodynamic lubrication. There is no controller implemented. It also acts as backup in case of failure of the radial oil injection system. This regime is utilized for benchmarking. The Hybrid Lubrication Regime: in this regime, which is one of the research objectives of this work, the high pressure unit is turned on and the hydrostatic contribution to the pressure build up is enabled. Depending on the servovalve's spool position, the high pressurized oil can be permanently injected by different pad combinations, leading to a change of the journal equilibrium position within the "x-y" plane and hence on the bearing dynamic properties. For horizontal machines, injecting from bottom pads has shown to produce a vertical bearing softening [40, and to reduce the system response amplitude [25]. In general terms, the higher the supply pressure the easier it

\footnotetext{
${ }^{1}$ Other configurations may also be developed, such as multi-orifice pads [16, 35, 36, 37, or shifted nozzle pads 38 .
} 
is to change the journal equilibrium position. By using feedback signals, this regime can be aided by integral controllers to attain or maintain a predefined equilibrium, especially when servovalve dynamics are unequal [25].

The Active Lubrication Regime: if the control signals driving the servovalves are defined by a control law, then the hydrostatic fluid-film force exerted over the journal can be actively-controlled. This is achieved by using the system lateral movements or their estimates as feedback signals to synthesize classical or model-based control laws. This was carried out in [26] based on proportional-derivative controllers, which have been also used to demonstrate the bearing properties modification by control laws in [17, 19]. Provided a reliable rotor-bearing system model, system states can be estimated so that model-based state-feedback controllers can be designed and implemented.

Table 2: Conventional and controllable design parameters of the actively-lubricated bearing (ALB).

\begin{tabular}{lll}
\hline Conventional & & \\
Design Parameters & Value & Units \\
\hline Journal radius $(R)$ & 49.89 & $\mathrm{~mm}$ \\
Pad inner radius $\left(R_{p}\right)$ & 50 & $\mathrm{~mm}$ \\
Pad aperture angle $\left(\alpha_{p}\right)$ & 69 & $\mathrm{~mm}$ \\
Pad width $(L)$ & 100 & $\mathrm{~mm}$ \\
Pad thickness $(t)$ & 14 & $\mu \mathrm{m}$ \\
Nominal radial clearance $\left(C_{p}\right)$ & 110 & $\mu \mathrm{m}$ \\
Assembly radial clearance $\left(C_{b}\right)$ & 83 & $\%$ \\
Bearing preload $\left(m_{p}\right)$ & 25 & - \\
Pad offset & 0.5 & $\mathrm{bar}$ \\
Lubrication oil type & ISO VG22 & \\
Oil supply pressure & max. 2 & $\mathrm{Units}$ \\
\hline Controllable & & - \\
Design Parameters & Value & - \\
\hline Servovalve type & MOOG E760-912 & - \\
Servovalve configuration & 4 way, spool valve & $\mathrm{Hz}$ \\
Cut-off frequency $(210$ bar $)$ & 350 & $\mathrm{~Hz}$ \\
Cut-off frequency $(100$ bar $)$ & 260 & - \\
Damping ratio & 0.73 & $\mathrm{~mm}$ \\
Injection orifice diameter $\left(d_{0}\right)$ & 3.3 & $\mathrm{~mm}$ \\
Injection orifice length $\left(L_{0}\right)$ & 21 & - \\
Injector offset & 0.5 & $\mathrm{bar}$ \\
Oil supply pressure & max. 100 & \\
\hline
\end{tabular}




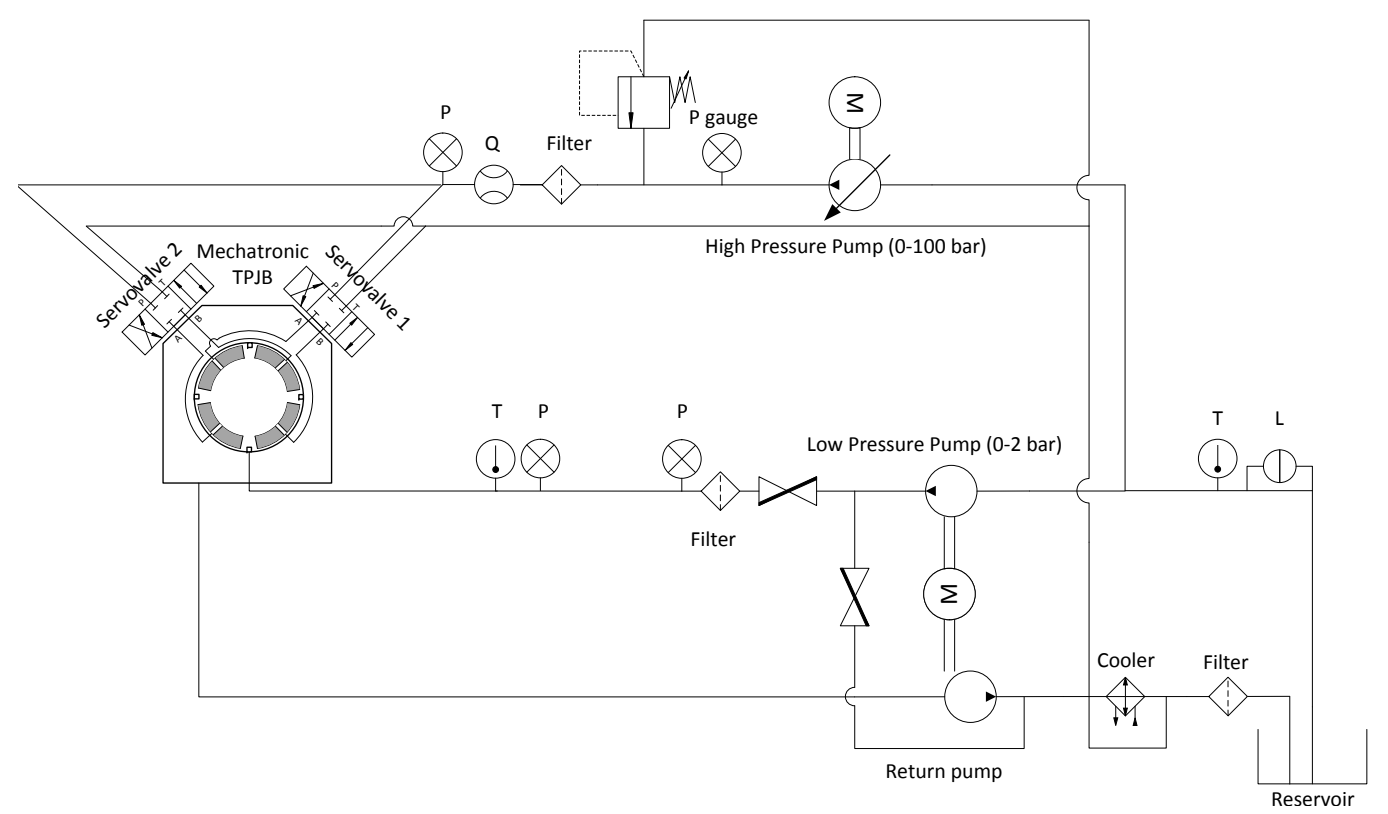

Figure 2: Hydraulic system layout. High pressure unit (for hybrid and active lubrication). Low pressure unit (for passive lubrication) and return unit.

\section{The Rotor - active TPJB Modelling}

The framework for the modelling of flexible rotor supported by active TPJBs when featuring the three lubrication regimes is set. Firstly, the generalized governing equations are obtained upon the linearisation of the equation of motion subjected to the fluid-film non-linear forces. Then, the modelling of the active TPJB through the ETHD approach is briefly addressed. Full bearing dynamic coefficients, which includes the pads and hydraulic dynamics, are reviewed for the three regimes. Lastly, the coupling of the active TPJB properties with a beam-based finite element model of the rotor is covered. Table 3 summarizes the contribution of dofs from each subsystem, which will be used throughout this section. The rotor subsystem introduces 4 dofs per node, two translational and two rotational. The pads introduce three dofs per pad: the pad tilt, bending and radial translation (due to the pivot flexibility). Finally, two extra dofs are introduced because of the hydraulic system, one per servovalve. 


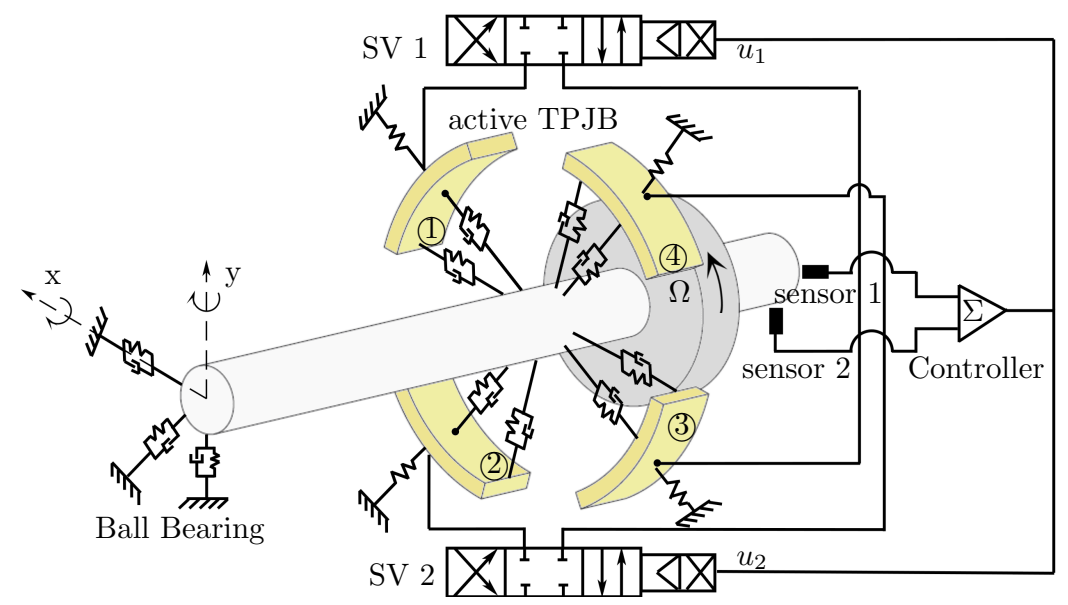

Figure 3: Flexible rotor - active TPJB system. Link between mechanic and hydraulic systems.

\subsection{Linking the rotor-bearing with the hydraulic dynamics for the different lubrication regimes}

Figure 3 presents the mechanical model of the integrated rotor-active TPJB system with the servo hydraulic subsystem. The link between them is the fluid-film force $\mathbf{f}_{p}(t)$ generated by the hydrodynamic and hydrostatic lubrications. These two effects together are responsible for: 1) the static bearing force - the load carrying capacity - and 2) two dynamics forces, namely: the bearing impedance force and the controllable force produced mainly due to variation of the hydraulic system control signal, affecting the hydrostatic injection of high pressurized oil. Uncoupling these forces is unphysical but mathematically convenient since it allows us to isolate the controllable force

Table 3: Dofs contribution from each subsystem to the whole rotor-active TPJB system. Generalized vector and its total contribution is also included.

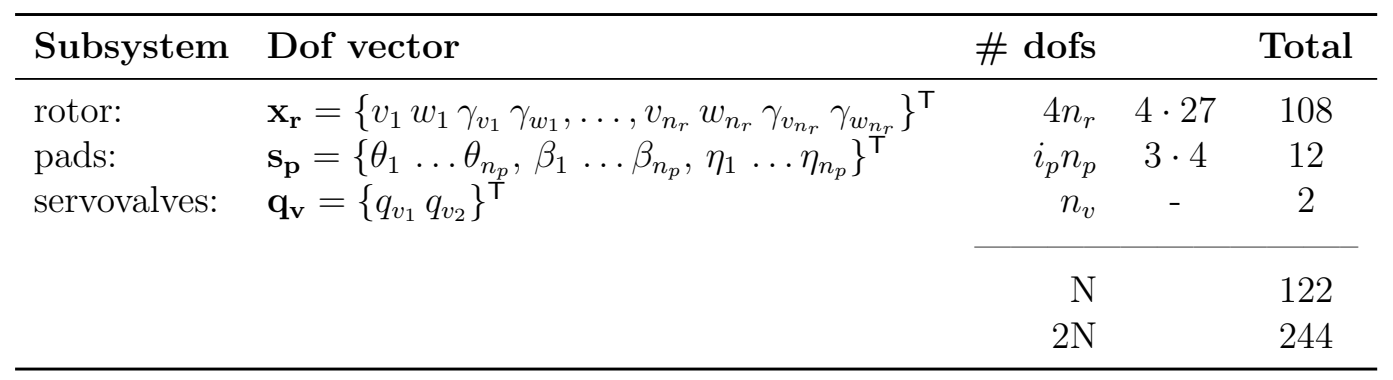


which can be experimentally characterized or theoretically calculated as presented in [41]. This approach has been utilized in works such as [21, 22, 42]. Another way to link the systems is by incorporating the hydraulic system as a part of the bearing dynamics. This leads to solving the bearing and servovalve dynamic equations together and to extending the amount of dofs defining the bearing dynamic properties by incorporating the spool-driven flow as a new dof. The way in which this link is made along with defining the generalized equation for the lubrication regimes are presented next.

Consider the equation of motion of the rotor subjected to the non-linear fluid-film forces $\mathbf{f}_{\mathbf{p}}$, the rotor distributed weight $\mathbf{w}$ and external dynamic forces $\mathbf{f}_{\text {ext }}$ :

$$
\mathbf{M} \ddot{\mathbf{x}}^{\prime}(t)-\Omega \mathbf{G} \dot{\mathbf{x}}^{\prime}(t)+\mathbf{K} \mathbf{x}^{\prime}(t)=\mathbf{w}+\mathbf{f}_{\mathbf{p}}\left(\mathbf{x}^{\prime \prime}, \dot{\mathbf{x}}^{\prime \prime}, \mathbf{q}_{\mathbf{v}}, \mathbf{u}, t\right)+\mathbf{f}_{e x t}(t)
$$

where $\mathbf{x}^{\prime}=\left\{\mathbf{x}_{\mathbf{r}} \mathbf{s}_{\mathbf{p}}\right\}^{\mathrm{T}}$ is the extended generalized vector which includes the rotor and pad's dofs, i.e. it does not include the hydraulic dofs. The fluid-film forces $\mathbf{f}_{\mathbf{p}}$ are a function of the journal translational dofs in which the bearing is connected (node $j$ ) and the pad's dofs, i.e. $\mathbf{x}^{\prime \prime}=\left\{v_{j} w_{j} \mathbf{s}_{\mathbf{p}}\right\}^{\top}$, as well as its time derivative. It is also a function of the spool-driven flow $\mathbf{q}_{\mathbf{v}}$ and the control signal $\mathbf{u}$. This force is simultaneously applied to the journal dofs and to the pad's dofs as forces and moments. The servovalve injection flow is a non-linear function of the spool position and the load pressure difference, i.e. $\mathbf{Q}_{\mathbf{v}}=\mathbf{Q}_{\mathbf{v}}\left(\mathbf{x}_{\mathbf{v}}(\mathbf{u}), \mathbf{P}_{\mathbf{L}}\right)$. This flow links the hydraulic and bearing dynamics through a set of constitutive equations. Upon a linearisation of the servovalve injection flow, the variations of the spool-driven flow $\boldsymbol{\Delta}_{\mathbf{q}_{\mathbf{v}}}$ are determined by the second order linearised equation governing the servovalve dynamics:

$$
\begin{aligned}
{\left[\begin{array}{ll}
1 & 0 \\
0 & 1
\end{array}\right]\left\{\begin{array}{l}
\Delta \ddot{q}_{v_{1}}(t) \\
\Delta \ddot{q}_{v_{2}}(t)
\end{array}\right\} } & +\left[\begin{array}{cc}
2 \xi_{v_{1}} \omega_{v_{1}} & 0 \\
0 & 2 \xi_{v_{2}} \omega_{v_{2}}
\end{array}\right]\left\{\begin{array}{l}
\Delta \dot{q}_{v_{1}}(t) \\
\Delta \dot{q}_{v_{2}}(t)
\end{array}\right\} \\
& +\left[\begin{array}{cc}
\omega_{v_{1}}^{2} & 0 \\
0 & \omega_{v_{2}}^{2}
\end{array}\right]\left\{\begin{array}{l}
\Delta q_{v_{1}}(t) \\
\Delta q_{v_{2}}(t)
\end{array}\right\}=\left[\begin{array}{cc}
\omega_{v_{1}}^{2} R_{v_{1}} & 0 \\
0 & \omega_{v_{2}}^{2} R_{v_{2}}
\end{array}\right]\left\{\begin{array}{l}
\Delta u_{1}(t) \\
\Delta u_{2}(t)
\end{array}\right\}
\end{aligned}
$$

The above equation written in matrix form reads:

$$
\mathbf{I} \Delta \ddot{\mathbf{q}}_{\mathbf{v}}(t)+\mathbf{2} \xi_{\mathbf{v}} \omega_{\mathbf{v}} \Delta \dot{\mathbf{q}}_{\mathbf{v}}(t)+\omega_{\mathbf{v}}^{2} \Delta \mathbf{q}_{\mathbf{v}}(t)=\omega_{\mathbf{v}}^{2} \mathbf{R}_{\mathbf{v}} \Delta \mathbf{u}(t)
$$

In order to linearise the Equation (1), it is Taylor expanded by rewriting it as a functional:

$$
\boldsymbol{\Pi}=\mathbf{M} \ddot{\mathbf{x}}^{\prime}(t)-\Omega \mathbf{G} \dot{\mathbf{x}}^{\prime}(t)+\mathbf{K} \mathbf{x}^{\prime}(t)-\mathbf{w}-\mathbf{f}_{\mathbf{p}}\left(\mathbf{x}^{\prime \prime}, \dot{\mathbf{x}}^{\prime \prime}, \mathbf{q}_{\mathbf{v}}, \mathbf{u}, t\right)-\mathbf{f}_{e x t}(t)
$$


and redefining the variables as variations around an equilibrium point:

$$
\begin{array}{lll}
\mathbf{x}^{\prime}=\mathbf{x}_{\mathbf{0}}^{\prime}+\Delta \mathbf{x}^{\prime} & \mathbf{q}_{\mathbf{v}}=\mathbf{q}_{\mathbf{v} 0}+\Delta \mathbf{q}_{\mathbf{v}} & \mathbf{f}_{\text {ext }}=\Delta \mathbf{f}_{\text {ext }} \\
\dot{\mathbf{x}}^{\prime}=\dot{\mathbf{x}}_{\mathbf{0}}^{\prime}+\Delta \dot{\mathbf{x}}^{\prime} & \mathbf{u}=\mathbf{u}_{\mathbf{0}}+\Delta \mathbf{u} \\
\ddot{\mathbf{x}}^{\prime}=\ddot{\mathbf{x}}_{\mathbf{0}}^{\prime}+\Delta \ddot{\mathbf{x}}^{\prime} & \mathbf{w}=\mathbf{w}_{\mathbf{0}}
\end{array}
$$

The Taylor series expansion of Equation (4) becomes:

$$
\begin{array}{r}
\boldsymbol{\Pi}=\boldsymbol{\Pi}_{0}+\left.\frac{\partial \boldsymbol{\Pi}}{\partial \ddot{\mathbf{x}}^{\prime}}\right|_{0} \Delta \ddot{\mathbf{x}}^{\prime}+\left.\frac{\partial \boldsymbol{\Pi}}{\partial \dot{\mathbf{x}}^{\prime}}\right|_{0} \Delta \dot{\mathbf{x}}^{\prime}+\left.\frac{\partial \boldsymbol{\Pi}}{\partial \mathbf{x}^{\prime}}\right|_{0} \Delta \mathbf{x}^{\prime}+\left.\frac{\partial \boldsymbol{\Pi}}{\partial \mathbf{q}_{\mathbf{v}}}\right|_{0} \Delta \mathbf{q}_{\mathbf{v}}+ \\
\left.\frac{\partial \boldsymbol{\Pi}}{\partial \mathbf{u}}\right|_{0} \Delta \mathbf{u}+\left.\frac{\partial \boldsymbol{\Pi}}{\partial \mathbf{f}_{e x t}}\right|_{0} \Delta \mathbf{f}_{e x t}+O\left(\Delta^{2}\right)
\end{array}
$$

The time variable $t$ has been omitted for simplicity and the weight and external forces are defined as purely static and dynamic loadings respectively. The left-hand side of Equation (6) is equal to zero by definition, i.e. $\Pi:=0$ for all variables. On the right-hand side, the terms higher than second order are disregarded, i.e. $O\left(\Delta^{2}\right) \cong 0$. Thus, at the equilibrium point at which $\ddot{\mathrm{x}}_{\mathbf{0}}^{\prime}=\dot{\mathrm{x}}_{\mathbf{0}}^{\prime}=\mathbf{0}$, it can be written:

$$
\Pi_{0}=\mathbf{K x}_{\mathbf{0}}^{\prime}-\mathbf{w}_{0}-\mathbf{f}_{\mathbf{p}}\left(\mathbf{x}_{\mathbf{0}}^{\prime \prime}, \mathbf{0}, \mathbf{q}_{\mathbf{v} \mathbf{0}}, \mathbf{u}_{0}\right)=\mathbf{0}
$$

The Jacobian terms are determined as:

$$
\begin{array}{lll}
\left.\frac{\partial \mathbf{\Pi}}{\partial \ddot{\mathbf{x}}^{\prime}}\right|_{0}=\mathbf{M} & \left.\frac{\partial \mathbf{\Pi}}{\partial \mathbf{x}^{\prime}}\right|_{0}=\mathbf{K}-\frac{\partial \mathbf{f}_{p}}{\partial \mathbf{x}^{\prime}} & \left.\frac{\partial \boldsymbol{\Pi}}{\partial \mathbf{u}}\right|_{0}=\frac{\partial \mathbf{f}_{p}^{0}}{\partial \mathbf{u}} \\
\left.\frac{\partial \boldsymbol{\Pi}}{\partial \dot{\mathbf{x}}^{\prime}}\right|_{0}=-\Omega \mathbf{G}-\frac{\partial \mathbf{f}_{p}}{\partial \dot{\mathbf{x}}^{\prime}} & \left.\frac{\partial \boldsymbol{\Pi}}{\partial \mathbf{q}_{\mathbf{v}}}\right|_{0}=\frac{\partial \mathbf{f}_{p}}{\partial \mathbf{q}_{\mathbf{v}}} & \left.\frac{\partial \boldsymbol{\Pi}}{\partial \mathbf{f}_{\text {ext }}}\right|_{0}=-1
\end{array}
$$

where the variation of the fluid-film forces due to the variation of a control signal is regarded as nil since there is not direct dependency. By replacing the terms of Equation (8) into Equation (6), the general equation of motion around the equilibrium can be sorted out as:

$$
\begin{aligned}
& {\left[\begin{array}{cc}
\mathbf{M} & \mathbf{0} \\
\mathbf{0} & \mathbf{I}
\end{array}\right]\left\{\begin{array}{c}
\Delta \ddot{\mathbf{x}}^{\prime} \\
\Delta \ddot{\mathbf{q}}_{\mathbf{v}}
\end{array}\right\}+\left(\left[\begin{array}{cc}
-\Omega \mathbf{G} & \mathbf{0} \\
\mathbf{0} & \mathbf{0}
\end{array}\right]+\left[\begin{array}{cc}
-\frac{\partial \mathbf{f}_{p}}{\partial \dot{\mathbf{x}}^{\prime}} & \mathbf{0} \\
\mathbf{0} & \mathbf{2} \xi_{\mathbf{v}} \omega_{\mathbf{v}}
\end{array}\right]\right)\left\{\begin{array}{c}
\Delta \dot{\mathbf{x}}^{\prime} \\
\Delta \dot{\mathbf{q}}_{\mathbf{v}}
\end{array}\right\}+} \\
& +\left(\left[\begin{array}{cc}
\mathbf{K} & \mathbf{0} \\
\mathbf{0} & \mathbf{0}
\end{array}\right]+\left[\begin{array}{cc}
-\frac{\partial \mathbf{f}_{p}}{\partial \mathbf{x}^{\prime}} & \frac{\partial \mathbf{f}_{p}}{\partial \mathbf{q}_{\mathbf{v}}} \\
\mathbf{0} & \omega_{\mathbf{v}}^{2}
\end{array}\right]\right)\left\{\begin{array}{c}
\Delta \mathbf{x}^{\prime} \\
\Delta \mathbf{q}_{\mathbf{v}}
\end{array}\right\}=\left[\begin{array}{c}
\mathbf{0} \\
\omega_{\mathbf{v}}^{\mathbf{2}} \mathbf{R}_{\mathbf{v}}
\end{array}\right] \Delta \mathbf{u}+\left[\begin{array}{c}
\Delta \mathbf{f}_{e x t} \\
\mathbf{0}
\end{array}\right]
\end{aligned}
$$


In Equation (9) the variation of the fluid-film forces due to variation of the bearing displacement, velocities and spool-driven flow as well as the parameters from the servovalve dynamics represents the bearing dynamic stiffness and damping properties of an active TPJB for a defined equilibrium $\Pi_{0}$, i.e.:

$$
\left.\mathbf{K}\right|_{\Pi_{0}}=\left[\begin{array}{cc}
-\frac{\partial \mathbf{f}_{\mathbf{p}}}{\partial \mathbf{x}^{\prime}} & \frac{\partial \mathbf{f}_{\mathbf{p}}}{\partial \mathbf{q}_{\mathbf{v}}} \\
\mathbf{0} & \omega_{\mathbf{v}}^{2}
\end{array}\right] ;\left.\quad \mathbf{D}\right|_{\Pi_{0}}=\left[\begin{array}{cc}
-\frac{\partial \mathbf{f}_{\mathbf{p}}}{\partial \dot{\mathbf{x}}^{\prime}} & \mathbf{0} \\
\mathbf{0} & \mathbf{2} \xi_{\mathbf{v}} \omega_{\mathbf{v}}
\end{array}\right]
$$

These full bearing matrices of Equation (10) are constant, i.e. they are not frequency dependent, and are obtained through a perturbation analysis of an ETHD modelling for controllable bearing as presented by [19]. These matrices can be directly plugged into Equation (9), with previous sorting and zero-padding. The link between the rotor-bearing and the hydraulic dynamics is made through the columns of the stiffness matrix $\frac{\partial \mathbf{f}_{\mathbf{p}}}{\partial \mathbf{q}_{\mathrm{v}}}$, which link the dofs of the servovalve with the rotor-bearing system, and it represents the variation of the fluid-film forces due to the variation of the spool-driven flow. With slight abuse of notation to disregard $\Delta$, Equation (9) is rewritten as:

$$
\mathbf{M} \ddot{\mathbf{x}}+\left(\left.\mathbf{D}\right|_{\Pi_{0}}-\Omega \mathbf{G}\right) \dot{\mathbf{x}}+\left(\mathbf{K}+\left.\mathbf{K}\right|_{\Pi_{0}}\right) \mathbf{x}=\mathbf{W u}+\mathbf{f}_{e x t}
$$

where $\mathbf{x}=\left\{\mathbf{x}^{\prime} \mathbf{q}_{\mathbf{v}}\right\}^{\mathrm{T}}=\left\{\mathbf{x}_{\mathbf{r}} \mathbf{S}_{\mathbf{p}} \mathbf{q}_{\mathbf{v}}\right\}^{\mathrm{T}}$ considers all dofs of the system, see Table 3. And the control input matrix $\mathbf{W}$ only depends on the supply pressure $P_{s}$ of the injection system which defines the servovalve natural frequency and input gain. By considering Equation (7) for the steady-state equilibrium and Equation (11) for the vibrations around it, it is obtained for:

- The passive lubrication $\left({ }^{p}\right)$ : in this case the hydraulic unit is off and there is no control signal $\mathbf{u}=\mathbf{0}$, nor variable spool-driven flow $\mathbf{q}_{\mathbf{v}}$, thus:

$$
\begin{array}{r}
\Pi_{0}^{p}=\mathbf{K} \mathbf{x}_{0}^{p}-\mathbf{w}_{0}-\mathbf{f}_{p}\left(\mathbf{x}_{0}^{p}, \mathbf{0}, \mathbf{q}_{\mathbf{v} 0}^{p}, \mathbf{0}\right)=0 \\
\mathbf{M} \ddot{\mathbf{x}}^{\prime}+\left(\left.\mathbf{D}\right|_{\Pi_{0}^{p}}-\Omega \mathbf{G}\right) \dot{\mathbf{x}}^{\prime}+\left(\mathbf{K}+\left.\mathbf{K}\right|_{\Pi_{0}^{p}} ^{p}\right) \mathbf{x}^{\prime}=\mathbf{f}_{e x t}
\end{array}
$$

- The hybrid lubrication $\left({ }^{h}\right)$ : in this case the hydraulic unit is on, therefore the equilibrium point changes due to the injection of a flow function of a 
constant control signal $\mathbf{u}_{0}$, thus:

$$
\begin{array}{r}
\boldsymbol{\Pi}_{0}^{h}=\mathbf{K} \mathbf{x}_{0}^{h}-\mathbf{w}_{0}-\mathbf{f}_{p}\left(\mathbf{x}_{0}^{h}, \mathbf{0}, \mathbf{q}_{\mathbf{v} 0}^{h}, \mathbf{u}_{0}\right)=0 \\
\mathbf{M} \ddot{\mathbf{x}}^{\prime}+\left(\left.\mathbf{D}\right|_{\Pi_{0}^{h}}-\Omega \mathbf{G}\right) \dot{\mathbf{x}}^{\prime}+\left(\mathbf{K}+\left.\mathbf{K}\right|_{\Pi_{0}^{h}}\right) \mathbf{x}^{\prime}=\mathbf{f}_{e x t}
\end{array}
$$

A common case is when the spool is centred and the leakage flow is injected, hence $\mathbf{u}_{\mathbf{0}}=\mathbf{0}$ and $\mathbf{q}_{\mathbf{v} 0}^{h}=\mathbf{q}_{\text {leak }}$. This is referred to as the leakage case.

- The active lubrication $\left(^{a}\right)$ : in this case the equilibrium position is regarded as the same as in the previous one, hence $\Pi_{0}^{a}=\Pi_{0}^{h}$; but in addition, there is a controllable fluid-film force exerted on the system due to the spool-driven flow variations $\mathbf{q}_{\mathbf{v}}$ driven by a control signal $\mathbf{u}$, therefore:

$$
\begin{array}{r}
\Pi_{0}^{a}=\mathbf{\Pi}_{0}^{h} \\
\mathbf{M} \ddot{\mathbf{x}}+\left(\left.\mathbf{D}\right|_{\Pi_{0}^{a}}-\Omega \mathbf{G}\right) \dot{\mathbf{x}}+\left(\mathbf{K}+\left.\mathbf{K}\right|_{\Pi_{0}^{a}}\right) \mathbf{x}=\mathbf{W} \mathbf{u}+\mathbf{f}_{e x t}
\end{array}
$$

Equations (12), (13) and (14) set the mathematical modelling framework for the analysis of the different lubrication regimes developed with the active TPJB. This implies that the bearing dynamic properties $\left.\mathbf{D}\right|_{\Pi_{0}}$ and $\left.\mathbf{K}\right|_{\Pi_{0}}$ are determined distinctly for the passive and every injection combination of the hybrid lubrication regime, which indeed determine a new journal equilibrium. In the case of the active lubrication regime, the same bearing coefficients calculated for the hybrid case can be utilized. Naturally, the passive lubrication regime defined by Equation (12), is used as a benchmark when specifying the advantage or drawbacks of the other regimes. Moreover, the active lubrication regime is the only one which includes the variation of the spool-driven flow $\mathbf{q}_{\mathbf{v}}$, while for passive and hybrid ones it only influences the equilibrium position through the constant flow $\mathbf{q}_{\mathbf{v} 0}$. As aforementioned, this work focuses on the hybrid lubrication, Equation (13), aiming at describing how the change of the journal equilibrium position $\Pi_{0}^{h}$, and hence the bearing dynamic properties, affect the entire rotor-bearing system response. The active lubrication with model-based controllers, based on Equation (14), is treated in part II. 


\subsection{Modelling the Active TPJB}

Lund [43], Lund and Thomsen [44, Springer [45] and Allaire et al. [46], among others, have provided a way of calculating the frequency dependence synchronously reduced as well as the full bearing force coefficients; the latter by including the pad dofs in the perturbation analysis thus eliminating the frequency dependence. Alongside the computational development these first isothermal models incorporated thermal and compliance effects in a more accurate model for conventional TPJB, the elasto-thermohydrodynamic (ETHD) model [43, 46, 47, 48, 49, 50. Regarding the active TPJBs, the initial isothermal modelling proposed by Santos and Russo [15] has been extended by the subsequent contributions of Santos and Nicoletti [16] (THD) and Santos and Haugaard [17] (EHD) to finally bridge the gap between both approaches in the ETHD formulation with the works of Varela et al. [18, 19]. The main ETHD equations are listed below.

- The Modified Reynolds Equation: for modelling the fluid-film pressure distribution in active TPJB by incorporating the high pressure oil flow injection as an equivalent perturbation of the velocity field [15].

- The Energy Equation for Active Lubrication: for modelling the local variation of viscosity of the fluid-film as a function of the oil film temperature, also affected by the oil jet injection [16].

- The Pad Equation of Motion: A pseudo modal reduction of the pad finite element formulation to incorporate the pad and pivot compliance in the modelling [17].

- The Servovalve Dynamics: A second order differential equation which relates to high pressure inflow as a function of the servovalve control signal [39] (already presented in Equation (3)).

The joint numerical solution of the listed equations, by the finite element method, leads to the calculation of the fluid-film force $\mathbf{f}_{p}(t)$ in equilibrium due to fluid-film pressure build up. Subsequently, the perturbation of such a pressure distribution yields the full set of the bearing dynamic force coefficients.

For the passive and hybrid regimes, provided the operational conditions of load and velocity, the bearing force coefficients are calculated either by defining the injection flow $\mathbf{q}_{\mathbf{v}_{\mathbf{0}}}$ or the injection pressure $\mathbf{P}_{\mathbf{i n j}}$ on each nozzle, 
whichever variable is better known. For the passive one the injection pressure must be nil, i.e. $\mathbf{P}_{\mathbf{i n j}}=0$, which entails a negative flow $\mathbf{q}_{\mathbf{v}_{\mathbf{0}}}<0$. In the case of hybrid lubrication, it is simpler to set an injection flow defined by a constant control signal $\mathbf{q}_{\mathbf{v}_{\mathbf{0}}}\left(\mathbf{u}_{\mathbf{0}}\right)$. When this control signal is nil, the flow reduces to the leakage flow, i.e. $\mathbf{q}_{\mathbf{v}_{\mathbf{0}}}=\mathbf{q}_{\mathbf{l e a k}}$. In both regimes $\left(^{*}\right)$, the bearing force coefficients are $\left(2+i_{p} n_{p}\right) \times\left(2+i_{p} n_{p}\right)$ matrices, which written as a bearing impedance reads:

$$
\begin{aligned}
& \left.\tilde{\mathbf{H}}^{\mathbf{b}}\right|_{\boldsymbol{\Pi}_{\mathbf{0}}^{*}}=\left.\tilde{\mathbf{K}}^{\mathbf{b}}\right|_{\boldsymbol{\Pi}_{\mathbf{0}}^{*}}+\left.j \omega \tilde{\mathbf{D}}^{\mathbf{b}}\right|_{\boldsymbol{\Pi}_{\mathbf{0}}^{*}} \\
& \left.\left.\tilde{\mathbf{H}}^{\mathbf{b}}\right|_{\mathbf{\Pi}_{\mathbf{0}}^{*}}=\left[\begin{array}{cc}
\mathbf{H}_{\mathbf{j j}} & \mathbf{H}_{\mathbf{j s}} \\
\mathbf{H}_{\mathbf{s j}} & \mathbf{H}_{\mathbf{s s}}
\end{array}\right]=\left[\begin{array}{cc}
{\left[\begin{array}{cc}
H_{v_{j} v_{j}} & H_{v_{j} w_{j}} \\
H_{w_{j} v_{j}} & H_{w_{j} w_{j}}
\end{array}\right]} \\
\begin{array}{cccc}
H_{\theta_{1} v_{j}} & H_{\theta_{1} w_{j}} \\
\vdots & \vdots \\
H_{\eta_{n_{p} v_{j}}} & H_{\eta_{n_{p} w_{j}}}
\end{array}
\end{array}\right] \begin{array}{ccc}
H_{v_{j} \theta_{1}} & \cdots & H_{v_{j} \eta_{n_{p}}} \\
H_{w_{j} \theta_{1}} & \cdots & H_{w_{j} \eta_{n_{p}}} \\
H_{\theta_{1} \theta_{1}} & 0 & 0 \\
0 & \ddots & 0 \\
0 & 0 & H_{\eta_{n_{p}} \eta_{n_{p}}}
\end{array}\right]
\end{aligned}
$$

The above matrix is defined only in terms of the journal $\left\{v_{j} w_{j}\right\}^{\top}$ and pad's dofs $\mathbf{s}_{\mathbf{p}}$. Variation of the spool-driven flow $\mathbf{q}_{\mathbf{v}}$ is not included for these regimes. $\mathbf{H}_{\mathbf{j} \mathbf{j}}$ stands for the $2 \times 2$ sub-matrix associated with the active TPJB node (dark gray), $\mathbf{H}_{\mathbf{j s}}$ and $\mathbf{H}_{\mathbf{s j}}$ are $2 \times n$ and $n \times 2$ sub-matrices, respectively, which couple the journal dofs with the pad ones (light gray) and $\mathbf{H}_{\mathbf{s s}}$ is a diagonal sub-matrix associated only with the pad's dofs. The length of the pad's dofs vector depends on the number of pads $n_{p}$ and pad's modes $i_{p}$ being considered in the pseudo modal reduction, i.e. $n_{p} i_{p}$. For a four pad bearing and considering the pad modes under study, 12 pad's dofs are obtained which lead to a matrix of $14 \times 14$. In the case of active lubrication regime $\left({ }^{a}\right)$, the spool-driven flow of the servovalves is introduced and the matrix of Equation $(15 \mathrm{~b})$ is extended to a $\left(2+i_{p} n_{p}+n_{v}\right) \times\left(2+i_{p} n_{p}+n_{v}\right)$ 
matrix:

$$
\begin{aligned}
& \left.\tilde{\mathbf{H}}^{\mathrm{b}}\right|_{\Pi_{\mathbf{0}}^{\mathrm{a}}}=\left[\begin{array}{ccc}
\mathbf{H}_{\mathrm{jj}} & \mathbf{H}_{\mathbf{j s}} & \mathbf{H}_{\mathbf{j v}} \\
\mathbf{H}_{\mathrm{sj}} & \mathbf{H}_{\mathrm{ss}} & \mathbf{H}_{\mathrm{sv}} \\
\mathbf{0} & \mathbf{0} & \mathbf{H}_{\mathrm{vv}}
\end{array}\right]=\cdots \\
& {\left[\begin{array}{ccccccc}
H_{v_{j} v_{j}} & H_{v_{j} w_{j}} & H_{v_{j} \theta_{1}} & \cdots & H_{v_{j} \eta_{n_{p}}} & H_{v_{j} v_{1}} & H_{v_{j} v_{2}} \\
H_{w_{j} v_{j}} & H_{w_{j} w_{j}} & H_{w_{j} \theta_{1}} & \cdots & H_{w_{j} \eta_{n_{p}}} & H_{w_{j} v_{1}} & H_{w_{j} v_{2}} \\
H_{\theta_{1} v_{j}} & H_{\theta_{1} w_{j}} & H_{\theta_{1} \theta_{1}} & 0 & 0 & 0 \\
\vdots & \vdots & 0 & \ddots & 0 \\
H_{\theta_{1} v_{1}} & H_{\theta_{1} v_{2}} \\
\vdots & \vdots \\
0 & 0 & \cdots & 0 & 0 \\
0 & 0 & \cdots & 0 & 0 & & \vdots \\
H_{\eta_{n_{p} v_{j}} v_{1}} & H_{\eta_{n_{p} w_{j}}} & 0 & 0 & H_{\eta_{n_{p} v_{2}}} \\
0 & 0 & & H_{v_{1} v_{1}} & 0 \\
0 & H_{v_{2} v_{2}}
\end{array}\right]}
\end{aligned}
$$

where the term $\mathbf{H}_{\mathbf{v v}}$ (soft gray) accounts for the servovalve's dynamics and the terms $\mathbf{H}_{\mathbf{j v}}$ and $\mathbf{H}_{\mathbf{s v}}$ (dark gray) make the link between the hydraulic and mechanical systems. These full set of bearing force coefficients are to be used in the rotor-bearing model without any further reduction to avoid system under-modelling, and hence stability margin over estimation [51, 31].

\subsection{Coupled Model of the Flexible Rotor with Active TPJB Full Matrices}

The model of the rotor is based on a Euler-Bernoulli beam finite element approach for the shaft which accounts for the translational and angular movements of the nodes [52], i.e. 4 dofs per node. Discs, bushes and coupling hubs are incorporated as rigid discs adding mass and inertia at their respective nodes. If no structural damping is considered nor the bearing impedance, then the equation of motion for the rotor around an equilibrium point is written as follows:

$$
\mathbf{M}^{r} \ddot{\mathbf{x}}_{\mathbf{r}}-\Omega \mathbf{G}^{r} \dot{\mathbf{x}}_{\mathbf{r}}+\mathbf{K}^{r} \mathbf{x}_{\mathbf{r}}=\mathbf{f}_{e x t}^{r}
$$

where $\mathbf{x}_{\mathbf{r}}$ stands for a $4 n_{r} \times 1$ vector containing only the dofs of the rotor discretization as defined in Table 3 . Figure 4 depicts the discretization utilized highlighting the main nodes. Short elements do not pose numerical problems. The coupling of the linear bearing force coefficient matrices of the active TPJB entails a system dofs expansion. In the case of the passive or hybrid regimes, the generalized vector is augmented to account for the pad dofs as $\mathbf{x}^{\prime}=\left\{\mathbf{x}_{\mathbf{r}} \mathbf{s}_{\mathbf{p}}\right\}^{\top}$ and for active lubrication it is augmented to also account 


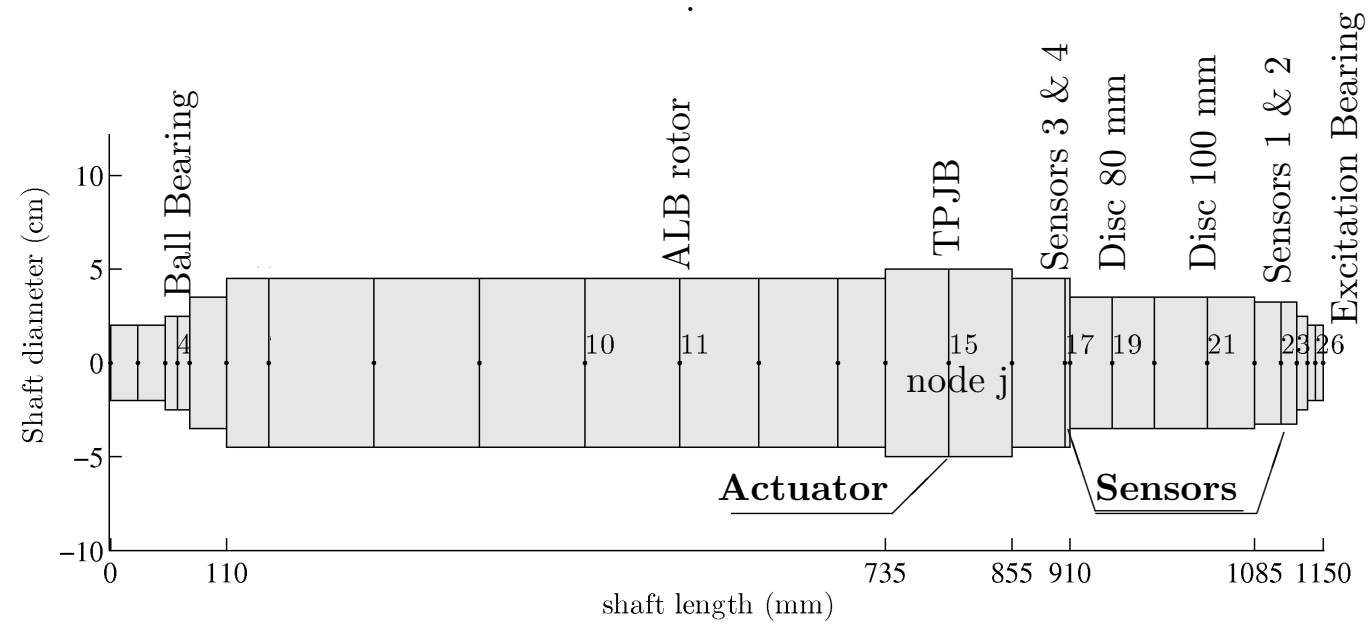

Figure 4: 26 shaft elements discretization with 27 nodes and 108 dofs. Main nodes are highlighted.

for the spool-driven flow as $\mathbf{x}=\left\{\mathbf{x}_{\mathbf{r}} \mathbf{S}_{\mathbf{p}} \mathbf{q}_{\mathbf{v}}\right\}^{\top}$. By zero-padding the system matrices $\mathbf{M}^{r}, \mathbf{G}^{r}, \mathbf{K}^{r}$ and vector $\mathbf{f}_{e x t}^{r}$, Equation (18) can be augmented as:

$$
\mathbf{M} \ddot{\mathbf{x}}^{*}-\Omega \mathbf{G} \dot{\mathbf{x}}^{*}+\mathbf{K} \mathbf{x}^{*}=\mathbf{f}_{e x t}
$$

where $\mathbf{x}^{*}=\mathrm{x}^{\prime}$ in the case of passive or hybrid regimes or $\mathbf{x}^{*}=\mathrm{x}$ in the active case. The bearing matrices $\left.\tilde{\mathbf{K}}^{\mathbf{b}}\right|_{\boldsymbol{\Pi}_{0}^{\mathbf{h}}}$ and $\left.\tilde{\mathbf{D}}^{\mathbf{b}}\right|_{\boldsymbol{\Pi}_{0}^{\mathbf{h}}}$ are sorted out in terms of the new augmented state vector $\mathbf{x}$ or $\mathbf{x}^{\prime}$ accordingly and zero-padded as follows:

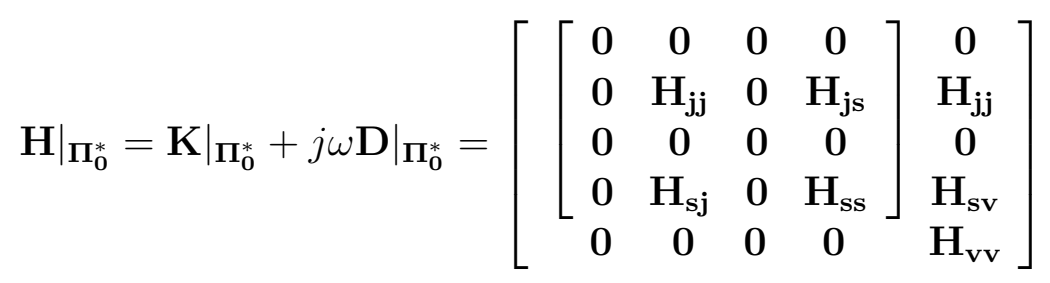

where in Equation (19) the inner matrix corresponds to the passive and hybrid cases (Equation (15b)), whereas the outer one does for the active (Equation (16)). Same procedure is done with the mass and inertia bearing matrix also yielded by the ETHD approach. Adding bearing matrices to the left hand side of Equation (18), the equation of motion of the rotor-bearing system is stated as:

$$
\mathbf{M} \ddot{\mathbf{x}}^{*}+\left(\left.\mathbf{D}\right|_{\Pi_{0}^{*}}-\Omega \mathbf{G}\right) \dot{\mathbf{x}}^{*}+\left(\mathbf{K}+\left.\mathbf{K}\right|_{\Pi_{0}^{*}}\right) \mathbf{x}^{*}=\mathbf{f}_{e x t}
$$

The above equation is generalized $\left(^{*}\right)$ and it is detailed for each lubrication regime in Equations (12), (13) and (14). 


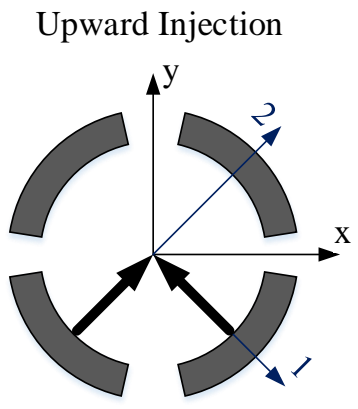

(a)

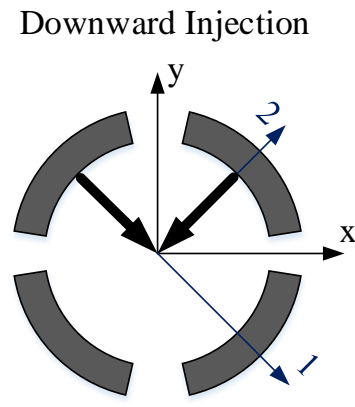

(b)

Figure 5: Upward and downward injection arrangements for a 4-pad bearing.

\section{The Hybrid Lubrication Regime}

The hybrid lubrication changes the system dynamic properties by injecting high pressurized oil into the bearing gap, which entails a change in the journal equilibrium position. This constant oil can be injected through different injection arrangements as discussed in [25]. Two of these are depicted in Figure 5 for a four pad bearing. These changes in equilibrium might be aided by integral controllers. Next, the influence of the regime on the system dynamic properties with and without the integral controller is revised and a model-based integral controller is presented, drawn from the work presented in paper II.

The equation of motion under hybrid lubrication (Equation 13 ) is rewritten in state-space formulation. Matrices $\left\{\mathbf{A}, \mathbf{B}, \mathbf{B}_{\mathbf{v}}, \mathbf{C}\right\}$ define the statespace formulation for the vector $\mathbf{X}=\{\mathbf{x} \dot{\mathbf{x}}\}^{\top}$. Furthermore, the system is pseudo-modal reduced and complex states separated to obtain an equivalent sate-space formulation $\left\{\tilde{\mathbf{A}}, \tilde{\mathbf{B}}, \tilde{\mathbf{B}}_{\mathbf{v}}, \tilde{\mathbf{C}}\right\}$ in terms of the modal vector $\mathbf{q}$ of the slowest system modes. These system dynamic properties are influenced by the changes in the journal equilibrium position $\Pi_{0}^{h}$ since each equilibrium position defines a unique pair of stiffness and damping properties, i.e. $\left.\tilde{\mathbf{K}}\right|_{\Pi_{0}^{h}}$ and $\left.\tilde{\mathbf{D}}\right|_{\Pi_{0}^{h}}$, for the ALB. Depending on how this equilibrium changing process is carried out regarding whether controllers are utilized or not, eigenvalues are affected differently, thus one can identify:

The Hybrid Lubrication Regime in Open-Loop . Under this configuration no control law is implemented. This implies that the bearing $\left(\left.\tilde{\mathbf{K}}\right|_{\Pi_{0}^{h}}\right.$ and $\left.\left.\tilde{\mathbf{D}}\right|_{\Pi_{0}^{h}}\right)$ and thus the rotor-bearing system properties $(\operatorname{det}\{\lambda \mathbf{I}-\mathbf{A}\}=0)$ are modified only due to the change in $\Pi_{0}^{h}$. 
The Hybrid Lubrication Regime in Closed-Loop. Under this configuration an integral control law is implemented to aid the journal position changes. In this case, in addition to the modifications already described in the openloop case $\left(\left.\tilde{\mathbf{K}}\right|_{\Pi_{0}^{h}}\right.$ and $\left.\tilde{\mathbf{D}}\right|_{\Pi_{0}^{h}}$ ), changes in the system are due to the closed-loop eigenvalues defined by:

$$
\operatorname{det}\left\{\lambda \mathbf{I}-\left[\begin{array}{cc}
\mathbf{A} & \mathbf{B K}_{i} \\
-\mathbf{C} & \mathbf{0}
\end{array}\right]\right\}=0
$$

\subsection{A Model-Based Integral Control Design}

Integral controllers do not require any system model to synthesize their gains, relying only on the direct comparison of the system output against a reference for obtaining them. However, some standard approaches of modelbased control can be utilized. The integral action, which ensures zero steadystate error, is included by system augmentation, i.e. by incorporating the time derivative of the integral state vector $\dot{\mathbf{q}}_{i}$ defined as the error between the desired position and the current one $\dot{\mathbf{q}}_{i}=\mathbf{e}=\mathbf{r}-\mathbf{Y}$, or $\dot{\mathbf{q}}_{\mathbf{i}}=\mathbf{r}-\mathbf{C q}$. If the control law is defined as $\mathbf{u}=\mathbf{K}_{\mathbf{i}} \mathbf{q}_{\mathbf{i}}$, then the closed-loop augmented system can be written as:

$$
\begin{aligned}
& \left\{\begin{array}{c}
\dot{\mathbf{q}} \\
\dot{\mathbf{q}}_{\mathbf{i}}
\end{array}\right\}=\left[\begin{array}{cc}
\mathbf{A} & \mathbf{B K}_{\mathbf{i}} \\
-\mathbf{C} & \mathbf{0}
\end{array}\right]\left\{\begin{array}{c}
\mathbf{q} \\
\mathbf{q}_{\mathbf{i}}
\end{array}\right\}+\left[\begin{array}{c}
\mathbf{B}_{v} \\
\mathbf{0}
\end{array}\right] \mathbf{v}_{\mathbf{1}}+\left[\begin{array}{l}
\mathbf{0} \\
\mathbf{I}
\end{array}\right] \mathbf{r} \\
& \{\mathbf{Y}\}=\left[\begin{array}{ll}
\mathbf{I} & \mathbf{0}
\end{array}\right]\left\{\begin{array}{c}
\mathbf{q} \\
\mathbf{q}_{\mathbf{i}}
\end{array}\right\}+\mathbf{v}_{\mathbf{2}}
\end{aligned}
$$

or in a reduced form $\left\{\tilde{\mathbf{A}}, \tilde{\mathbf{B}}_{\mathbf{v}}, \tilde{\mathbf{B}}_{\mathbf{r}}, \tilde{\mathbf{C}}\right\}$ for a state vector $\mathbf{Z}=\left\{\mathbf{q} \mathbf{q}_{\mathbf{i}}\right\}^{\top}$.

A linear-quadratic-regulator (LQR), which is an optimal control in terms of energy balance, is chosen since it provides an intuitive way to synthesize the integral gains by weighting only the integral states and the control signals in the steady-state cost function:

$$
\mathbf{J}=\int_{0}^{\infty}\left(\mathbf{Z}^{\top} \mathbf{Q Z}+\mathbf{u}^{\top} \mathbf{R} \mathbf{u}\right) d t
$$

where $\mathbf{Q}$ is the $n \times n$ state weighting diagonal matrix, which in this case has non-zero weighting constants only at the positions associated with the integral states $\mathbf{q}_{\mathbf{i}}$. $\mathbf{R}$ is a $2 \times 2$ matrix to weight the servovalve control signals. Both matrices are obtained via simulations. 


\section{Model Validation}

Theoretical results are reported jointly with their experimental counterpart to validate them. This is done for the system without discs configuration and featuring the passive and hybrid lubrication regimes. For both cases an angular velocity of $1000 \mathrm{rpm}$ and a pressure of 90 bar in the hybrid lubrication cases are considered. Results are presented as plots of modeshapes with their damped natural frequency and damping ratio for the non-stationary response and as frequency response functions (FRFs) for the stationary one. In the calculation of the bearing force coefficient matrices $\left.\mathbf{K}\right|_{\Pi_{0}^{h}}$ and $\left.\mathbf{D}\right|_{\Pi_{0}^{h}}$, presented in Appendix A for the leakage case of the hybrid lubrication regime, a pivot stiffness of $4 \cdot 10^{8}(\mathrm{~N} / \mathrm{m})$ is considered equally in all pads. The bearing inertia matrix $\mathbf{M}$ is also provided. Excitation is introduced to the system through the excitation bearing at node 26, dof 101 and 102, and the system response is obtained at the pedestal of sensors 1 and 2, which corresponds to the node 23, dof 89 and 90 . Figure 6 shows the first modes of the system without any disc featuring hybrid lubrication at $1000 \mathrm{rpm}$ and $90 \mathrm{bar}$ of pressure supply. These modes correspond to the conical and first bending modes, both forward and backward around $10 \mathrm{~Hz}$ and $210 \mathrm{~Hz}$ respectively. The conical mode in this particular case describes almost a straight line due to the weak gyroscopic effect at such speed. Furthermore, this mode has a damping ratio more than ten times larger than the first bending one, which explains its low influence in the FRFs.

Figures 7 and 8 report the FRFs under passive lubrication. Fair agreement is obtained with differences in the damped natural frequency and in the damping ratio mainly in the vertical direction. The mismatch in phase is increased at higher frequency due to what is seen as a linear increase of the experimental phase with excitation frequency. Similarly, Figures 9 and 10 show the FRFs in both directions for the system featuring the hybrid lubrication with 90 bar of supply pressure. In this case, the fitting of FRFs is better in relation to the amplitudes, with better results in the horizontal case. The same trend in the experimental phase is observed. It is considered that the model satisfies the requirement for developing controllers, bearing in mind the identified mismatching.

\section{Experimental Setup}

Experimental campaigns are carried out under two system configurations: by hanging none and one disc (80 mm disc), i.e., $400 \mathrm{~N}$ and $880 \mathrm{~N}$ of static 
$10.20 \mathrm{~Hz}, \xi=0.65, \mathrm{FW} 1000 \mathrm{rpm}$

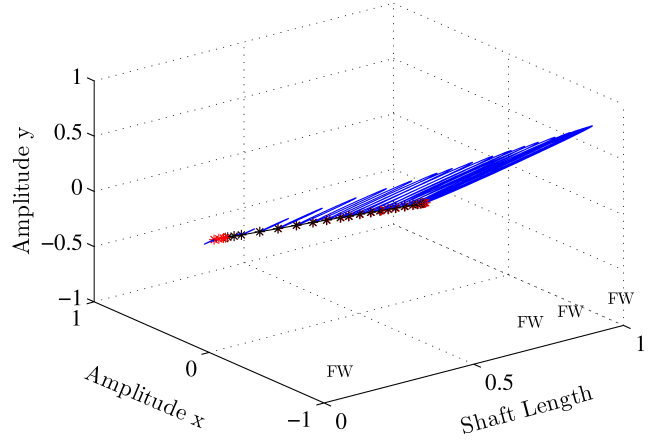

$209.41 \mathrm{~Hz}, \xi=0.05, \mathrm{BW} 1000 \mathrm{rpm}$

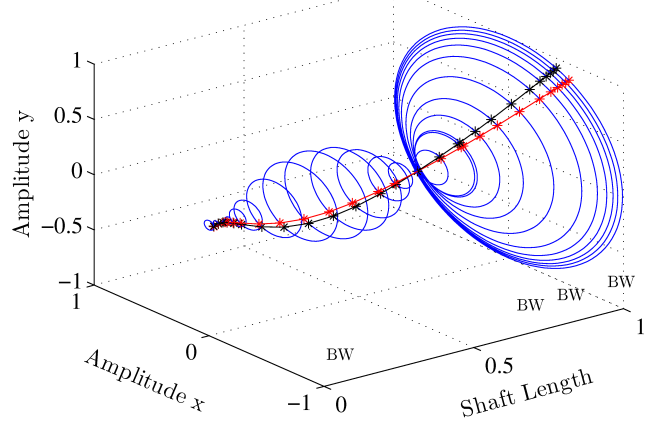

$10.21 \mathrm{~Hz}, \xi=0.65, \mathrm{BW} 1000 \mathrm{rpm}$

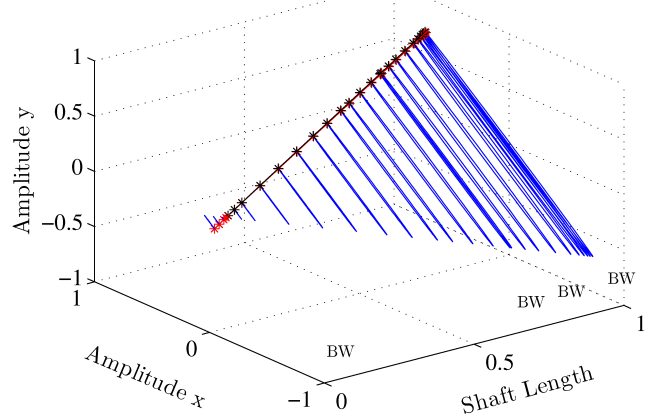

$209.78 \mathrm{~Hz}, \xi=0.05, \mathrm{FW} 1000 \mathrm{rpm}$

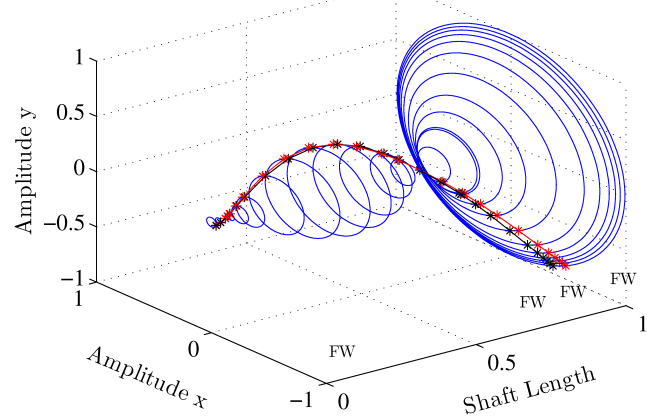

Figure 6: Theoretical modeshapes with their respective damped natural frequency and damping ratio. Hybrid lubrication regime at $1000 \mathrm{rpm}$ and 90 bar of supply pressure.

bearing loading. Three angular speeds are tested: $2000 \mathrm{rpm}$ and $4000 \mathrm{rpm}$ for the system without disc and $1000 \mathrm{rpm}$ with the system with one disc, which leads to an increase of the gyroscopic effect. To develop the hybrid lubrication regime 60 bar and 90 bar are used with no disc configuration and 100 bar with one disc. The experiments start when force and thermal equilibria are established. The system lateral response is obtained by sweeping a bidirectional chirp signal from 20 to $250 \mathrm{~Hz}$ in a 10 s linear ramp over 5 min. Other types of excitation signals can be used to reduce the application time required, such as Pseudo Random Binary Sequences (PRBS) or Schroeder Phased Harmonic Signals (SPHS) [53], and maybe tried in the future instead of the swept-sine signals used. The lateral movement is obtained at the pedestal of sensor 1 when exciting at the excitation bearing, see Figure 4 . FRFs are obtained with a Hanning window, $1 \mathrm{~Hz}$ of frequency resolution and 

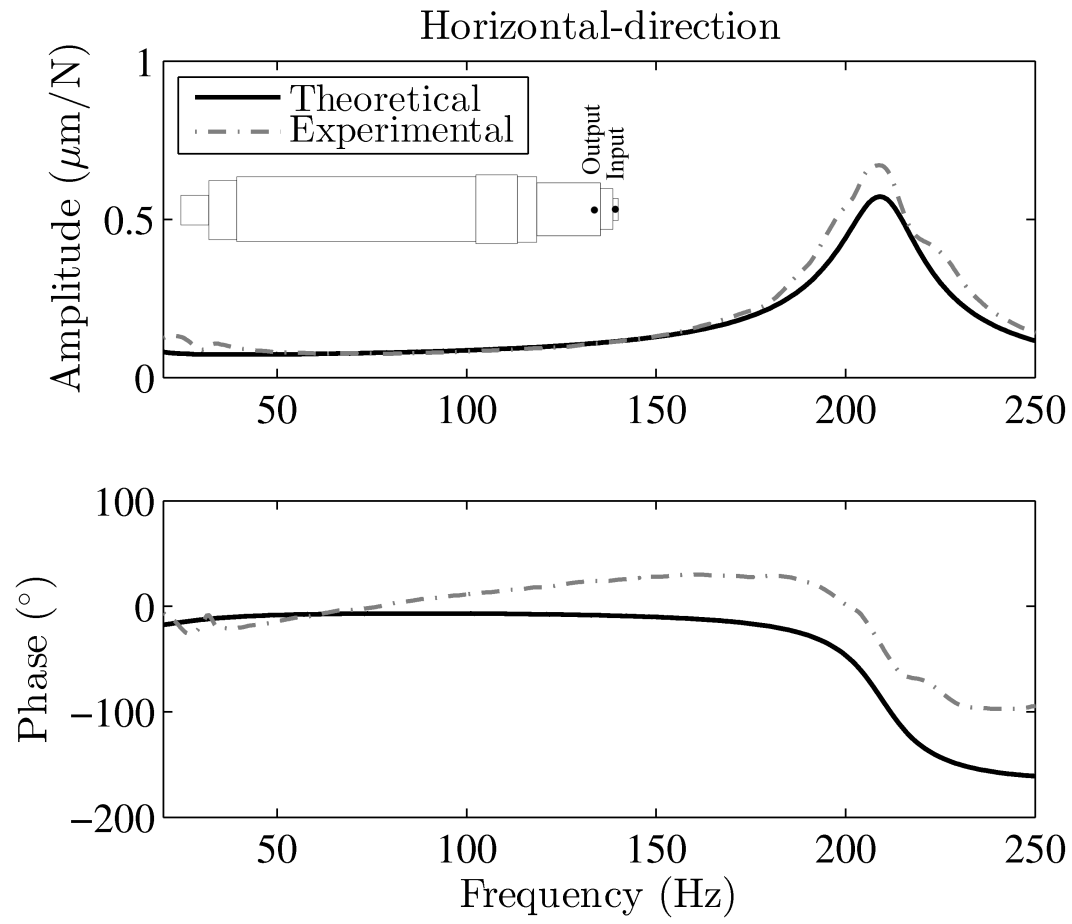

Figure 7: Theoretical and experimental FRFs under passive lubrication. Horizontal direction. Rotor without disc, $1000 \mathrm{rpm}$.

$50 \%$ of overlap.

\section{Results under Open-Loop Hybrid Lubrication}

The rotor without discs is firstly studied. No injection schemes are attempted in open-loop. Instead, the hybrid lubrication regimes obtained by injecting only the leakage flow are tested at two supply pressures. Figure 11 compares at $2000 \mathrm{rpm}$ the system response under hybrid lubrication regime with 60 and 90 bar against the conventional passive lubrication regime. The effectiveness of injecting constant oil aiming at improving the damping is evident at the resonance around $210 \mathrm{~Hz}$. Moreover, the higher the supply pressure, the more significant the vibration reduction obtained, in this case around 30\%. Results under the same conditions, but at $4000 \mathrm{rpm}$, are depicted in Figure 12. Some discrepancies can be spotted since a larger reduction is obtained with 60 bar rather than 90 bar. Nonetheless, both cases impose a vibration reduction with the hybrid lubrication when compared 

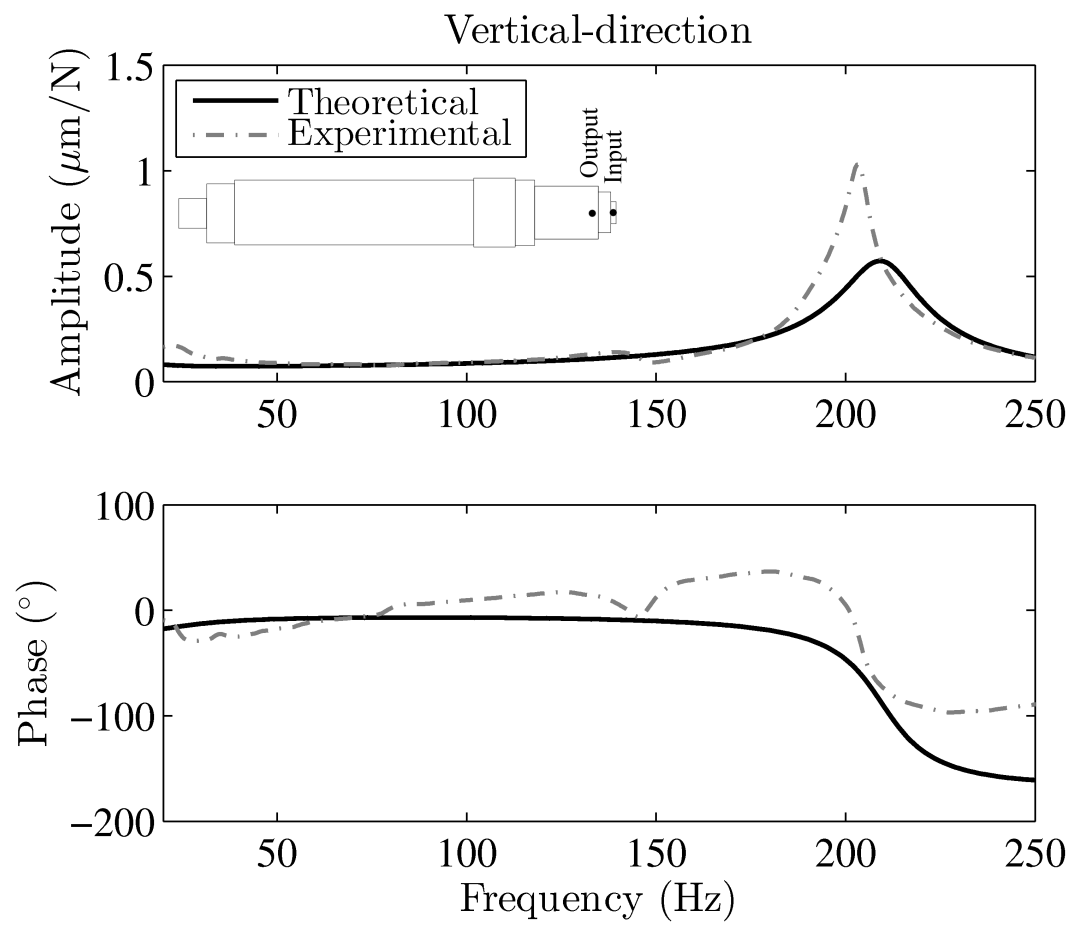

Figure 8: Theoretical and experimental FRFs under passive lubrication. Vertical direction. Rotor without disc, $1000 \mathrm{rpm}$.

against the passive one. To complement these last results, the FRFs in the vertical direction for passive and 90 bar hybrid case are depicted in Figure 13 with the expected reduction achieved by the hybrid lubrication. It is also noted that below $200 \mathrm{~Hz}$ new dynamics are taking place around $100 \mathrm{~Hz}$ for the passive case which is suppressed out with the hybrid lubrication regime.

\section{Results under Closed-Loop Hybrid Lubrication}

The rotor without discs is then studied in closed-loop configuration. The supply pressure is raised up to 100 bar for which the oil temperature reached around $58^{\circ} \mathrm{C}$ and the angular velocity is reduced to $1000 \mathrm{rpm}$. An integral controller synthesized upon the rotor-bearing model is utilized to feature upward and downward injection schemes, see Figure 5. The utilized weighting matrices are $\mathbf{Q}=\operatorname{diag}\left\{\mathbf{0}_{1 \times n}, 10^{8}, 10^{8}\right\}$ and $\mathbf{R}=\operatorname{diag}\left\{7 \cdot 10^{5}, 5 \cdot 10^{5}\right\}$. Figure 14 compares the leakage hybrid lubrication, an upward scheme with reference $\mathbf{r}=\{0,30\}^{\top}(\mu \mathrm{m})$ and a downward scheme with reference $\mathbf{r}=$ 

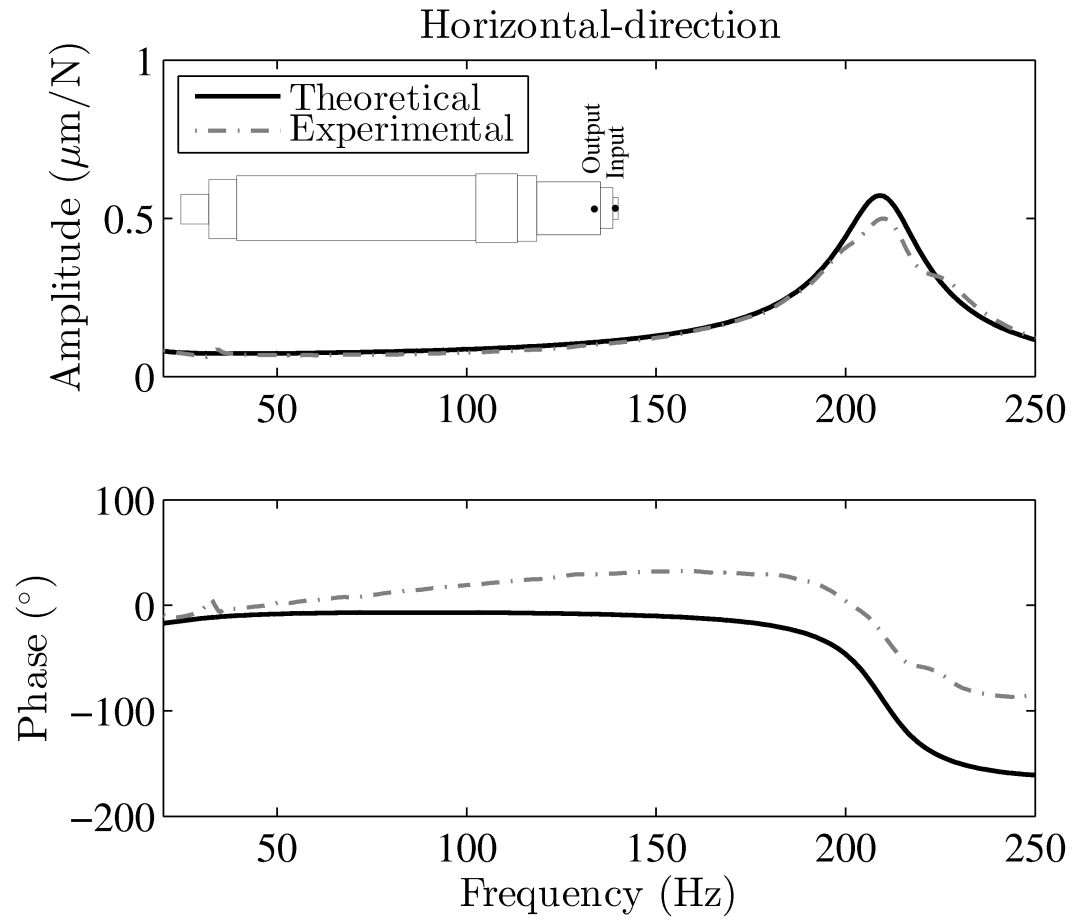

Figure 9: Theoretical and experimental FRFs under hybrid lubrication. Horizontal direction. Rotor without disc, $1000 \mathrm{rpm}$ and 90 bar and supply pressure.

$\{0,-50\}^{\top}(\mu \mathrm{m})$ against the passive case. Again, a main reduction is obtained after the hybrid regime is established, and a further vibration reduction can even be achieved if the rotor is lifted up, as is the case with the upward injection scheme. Such a reduction can be explained due to the extra oil injected in the pads supporting the load, at the bottom pads. Contrarily, an increase of the resonant peak or reduction of the damping ratio is observed when the rotor is pressed down by an increased force on the top pads under the downward injection scheme. As stated in the work [25], it is easier to move the journal downward which allowed us to set larger references in such a direction. Figure 15 complements the results by showing the FRFs when the system is loaded with one disc. In this case, results are also obtained in the horizontal direction when running at $1000 \mathrm{rpm}$. Only 90 bar are tested and an upward injection implemented. The trend in results is maintained, i.e. an upward injection scheme slightly damps the resonant zone when compared with the hybrid case, which in turn entails a significant global vibration 

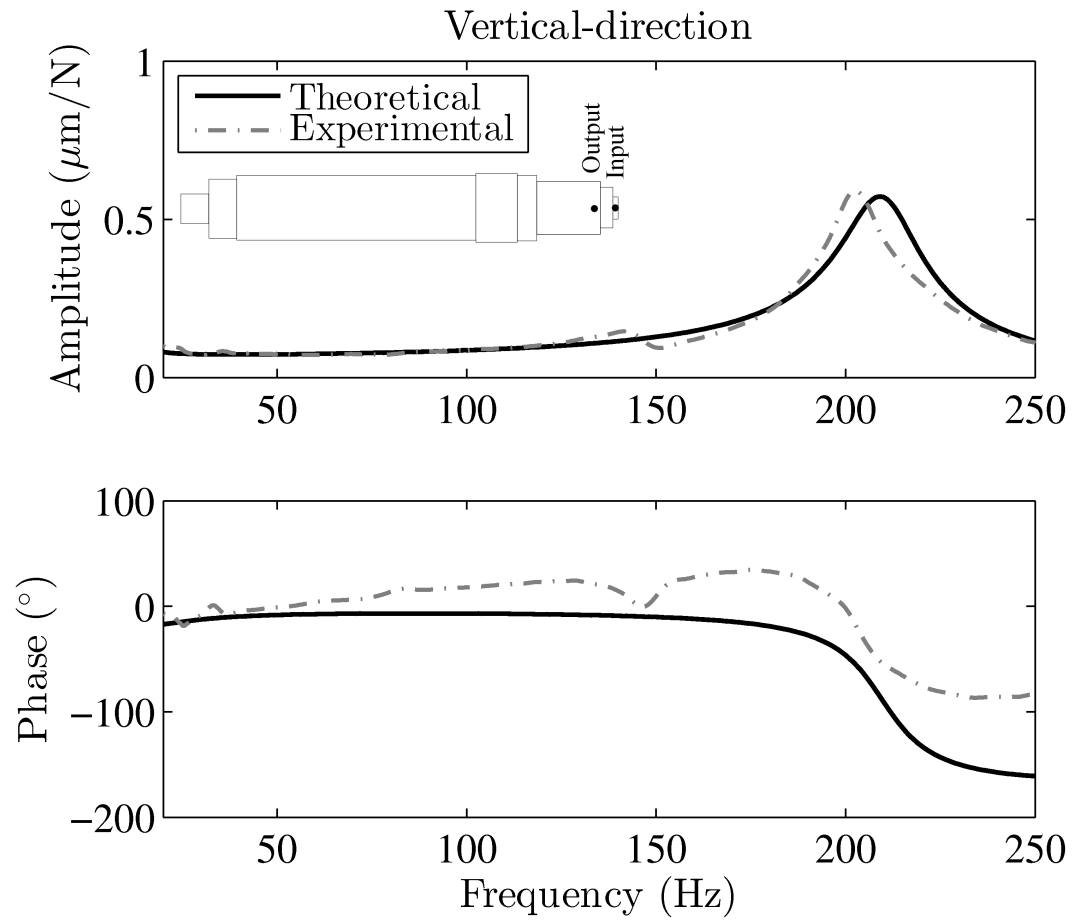

Figure 10: Theoretical and experimental FRFs under hybrid lubrication. Vertical direction. Rotor without disc, $1000 \mathrm{rpm}$ and 90 bar and supply pressure.

reduction when compared to the passive case.

\section{Conclusions}

In this work the modelling of a flexible rotor mounted on active TPJB is mathematically reviewed. Three possible cases of lubrication regimes are investigated: passive, hybrid and active. Special attention is paid to describing the link between the hydraulic and mechanical subsystems for each of the regimes. In the light of the theoretical treatment and experimental results exposed, it can be concluded:

- From a theoretical viewpoint, the validation of the whole rotor-bearing system dynamic response is considered satisfactory under the passive and hybrid lubrication regimes.

- Furthermore, it is established that the bearing force coefficients calculated for the hybrid regime and linearized around the same journal equilibrium 

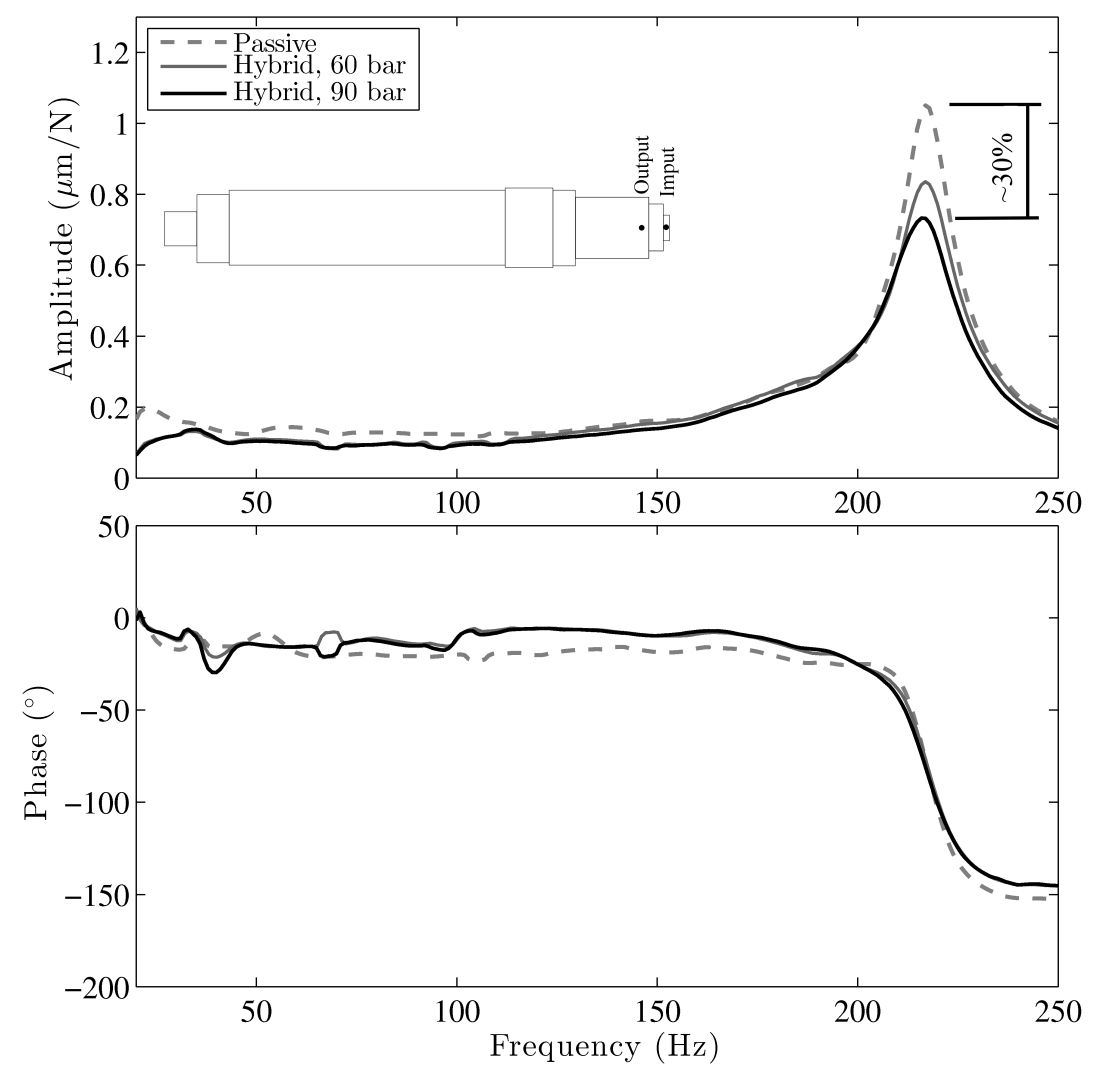

Figure 11: Experimental FRFs in the horizontal direction. Rotor without disc. 2000 rpm.

point, can be utilized for the active lubrication by further including the servovalve dynamics.

- From an experimental point of view, it is shown under different system configurations and operational conditions that improvement of the system's lateral dynamic response can be achieved by featuring the hybrid or adjustable lubrication in comparison to the passive regime. Even further reduction can be attained by establishing an upward injection scheme, either with or without integral control. Reductions of about 30\% were achieved around the resonant zone with the hybrid lubrication.

- Further vibration reductions might only be possible by adding feedback control to the lubrication regimes, as pursued in part II. 

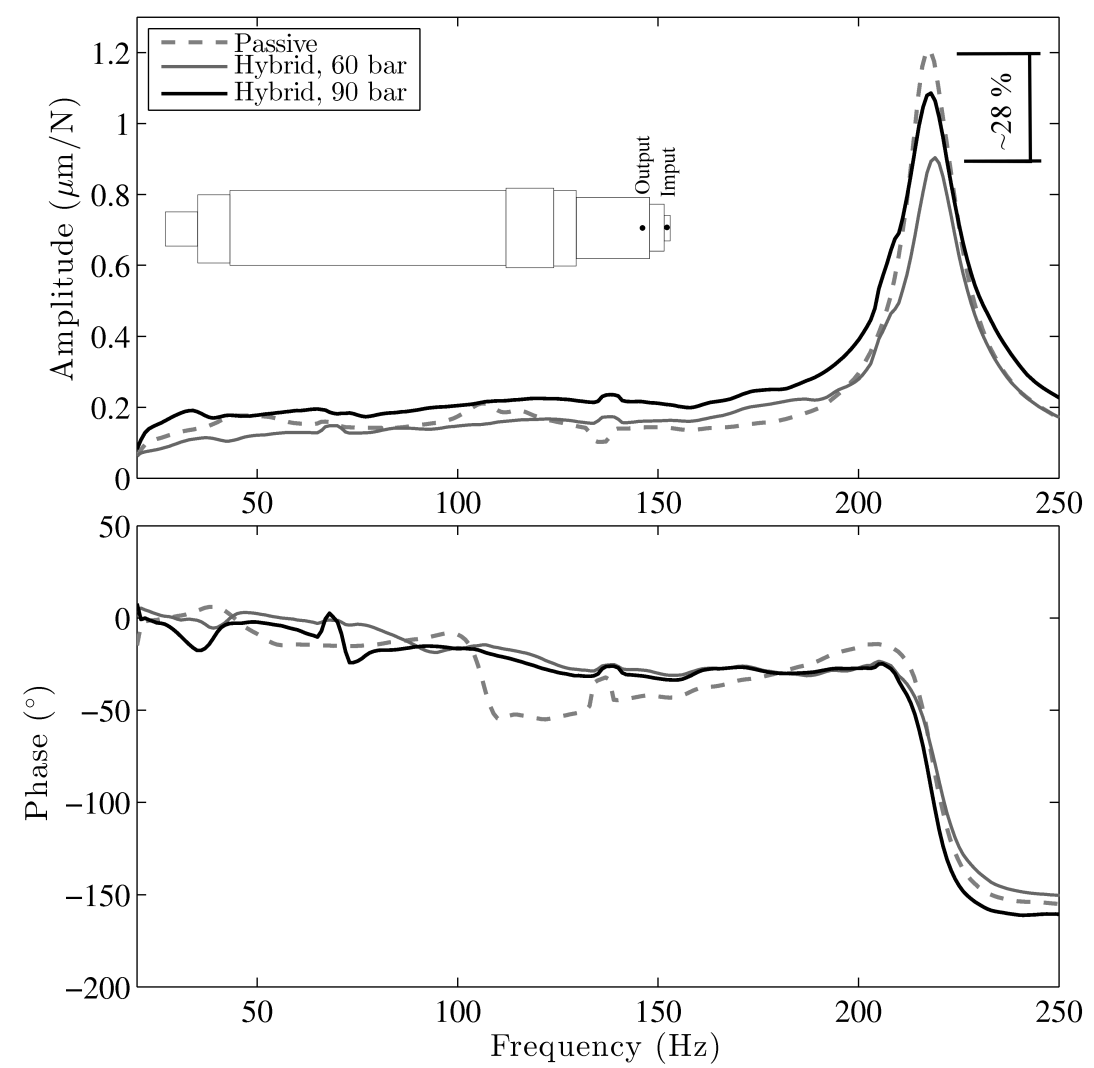

Figure 12: Experimental FRFs in the horizontal direction. Rotor without disc. 4000 rpm. 

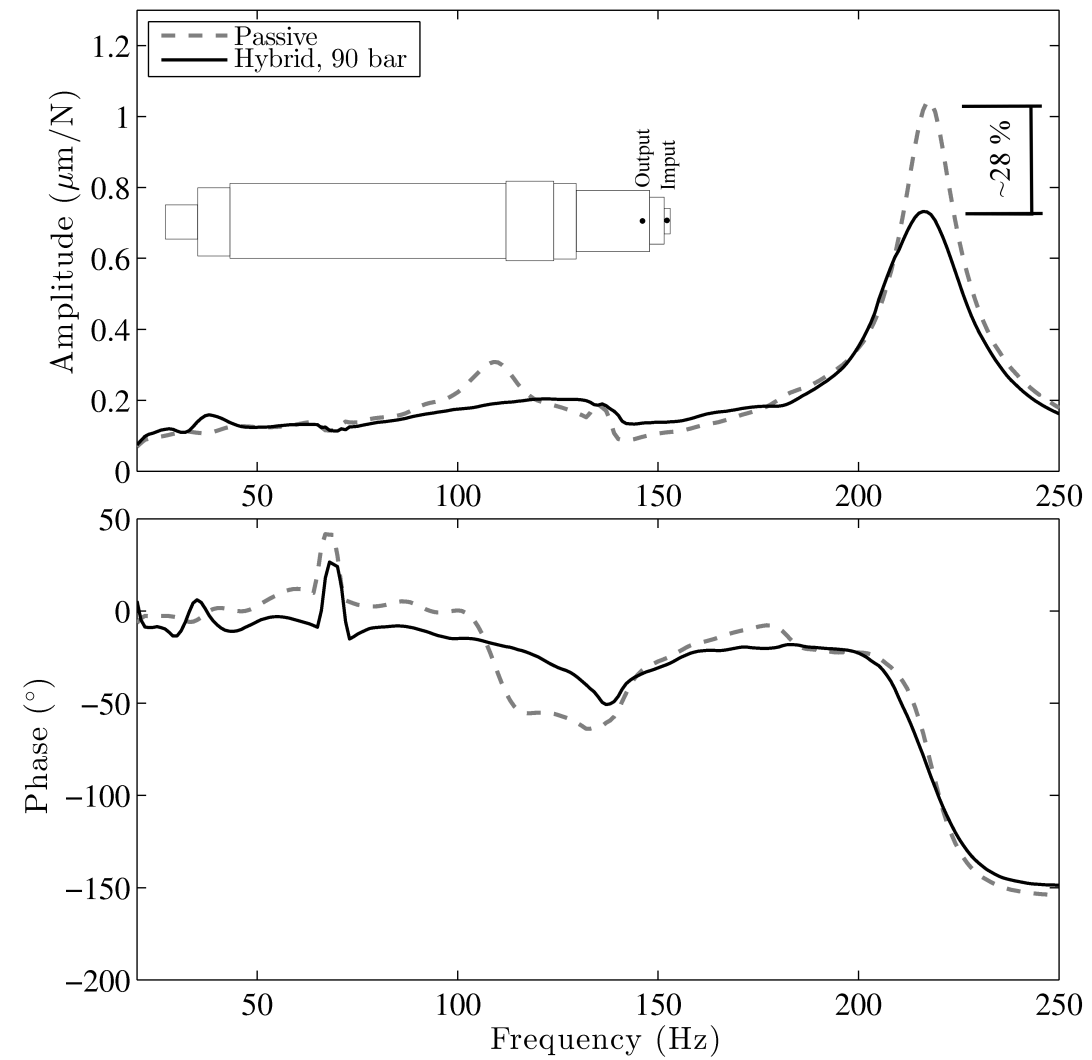

Figure 13: Experimental FRFs in the vertical direction. Rotor without disc. 4000 rpm. 

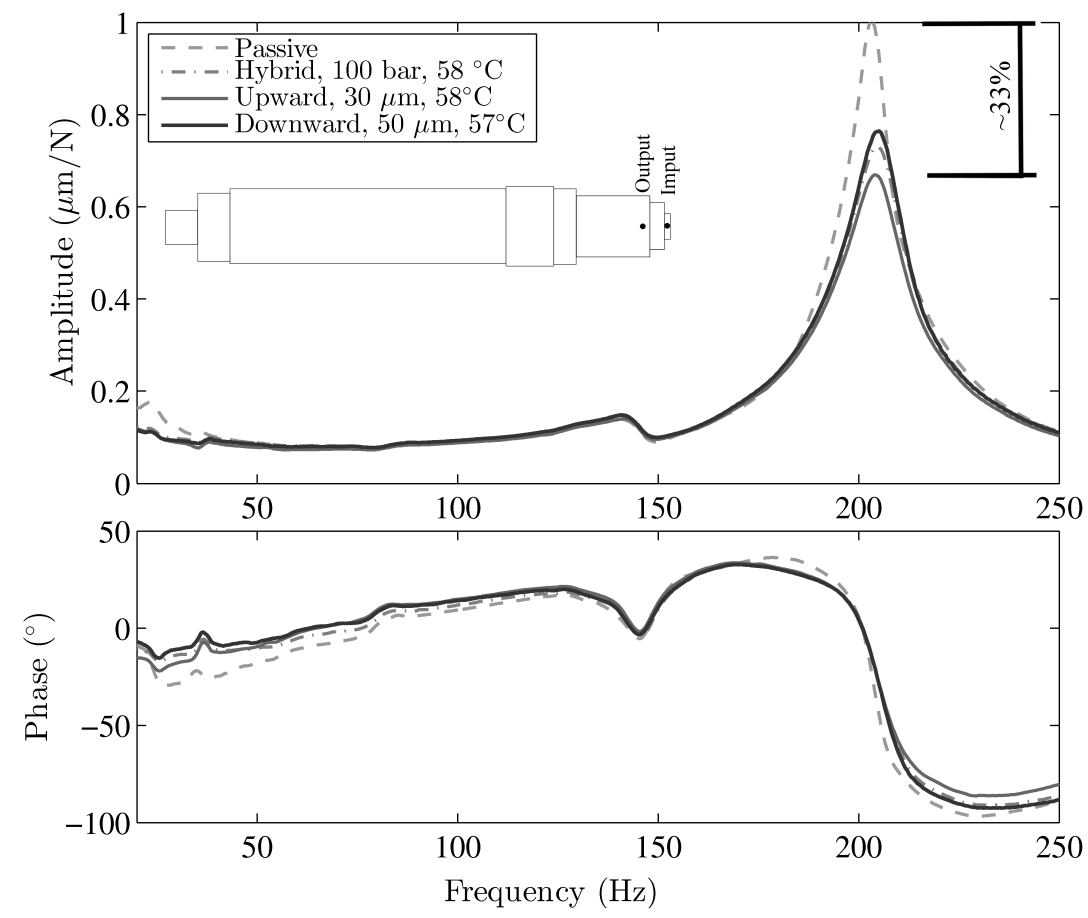

Figure 14: Experimental FRFs in the vertical direction. Closed-loop hybrid lubrication for the upward and downward schemes. Rotor without disc. $4000 \mathrm{rpm}$. 


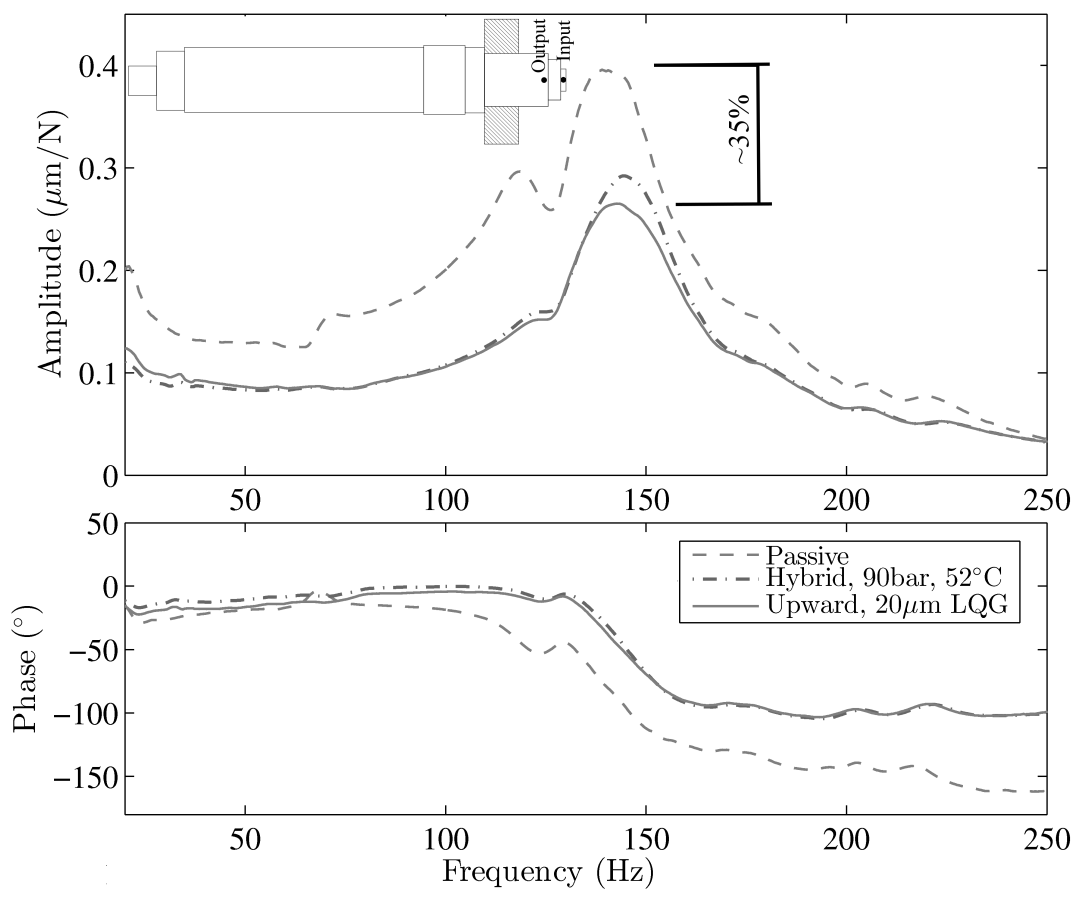

Figure 15: FRF in the horizontal direction. System with one disc. $1000 \mathrm{rpm}$. 


\section{References}

[1] Bleuler H, Cole M, Keogh P, Larsonneur R, Maslen E, Okada Y, Schweitzer G, Traxler A, Schweitzer G, Maslen EH, et al. . Magnetic bearings: theory, design, and application to rotating machinery. Springer Science \& Business Media, 2009.

[2] Ulbrich H, Anton E, Theory and application of magnetic bearings with integrated displacement and velocity sensors. In: IMechE 1984 C299/84, 1984, pp. 543-551.

[3] Morosi S, Santos IF. Active lubrication applied to radial gas journal bearings. part 1: Modeling. Tribology International 2011; 44(12): 1949 1958.

[4] Pierart FG, Santos IF.Active lubrication applied to radial gas journal bearings. part 2: Modelling improvement and experimental validation. Tribology International 2016; 96: 237-246.

[5] Horikawa O, Sato K, Shimokohbe A. An active air journal bearing. Nanotechnology 1992; 3(2): 84-90.

[6] Bently DE, Grant JW, Hanifan PC. Active controlled hydrostatic bearings for a new generation of machines. In: ASME Turbo Expo 2000: Power for Land, Sea, and Air, American Society of Mechanical Engineers, 2000; V002T03A011.

[7] Chasalevri A, Dohnal F. Improving stability and operation of turbine rotors using adjustable journal bearings. Tribology International 2016; 104(12): 369-382.

[8] Hagg AC.The influence of oil-film journal bearings on the stability of rotating machines. Journal of Applied Mechanics, Transactions of the ASME 1946; 13(3): A211-A220.

[9] Pope A, Healy S, Paper 11: Anti-vibration journal bearings. In: Proceedings of the Institution of Mechanical Engineers, Conference Proceedings. SAGE Publications 1966; 181: 98-115.

[10] Althaus J, Ulbrich H. A fast hydraulic actuator for active vibration control. In: IMechE 1992, C432/045, 1992; 141-148. 
[11] Ulbrich H, Althaus J. Actuator Design for Rotor Control. in: 12th Biennial conference on Mechanical Vibration and Noise. Montreal, Quebec, Canada. 1989; 17-22.

[12] Palazzolo A, Lin RR, Alexander RM, Kascak A, Montague J. Test and Theory for Piezoelectric Actuator-Active Vibration Control of Rotating Machinery. Journal of Vibration and Acoustics 1991; 113(April): 167175.

[13] Santos IF. Design and evaluation of two types of active tilting pad journal bearings. In: IUTAM Symposium on Active Control of Vibration 1994; 55: 583-594.

[14] Santos IF. On the Adjusting of the Dynamic Coefficients of Tilting-Pad Journal Bearings. STLE Tribology Transactions 1995; 38(3): 700-706.

[15] Santos IF, Russo FH. Tilting-pad journal bearings with electronic radial oil injection. Journal of Tribology 1998; 120(3): 583-594.

[16] Santos IF, Nicoletti R. THD analysis in tilting-pad journal bearings using multiple orifice hybrid lubrication. Journal of Tribology 1999; 121(4): 892-900.

[17] Haugaard AM, Santos IF, Elastohydrodynamics applied to active tiltingpad journal bearings, Journal of Tribology 2010; 132(2): 021702.

[18] Varela AC, Nielsen BB, Santos IF. Steady state characteristics of a tilting pad journal bearing with controllable lubrication: Comparison between theoretical and experimental results. Tribology International $2013 ; 58(1)$ : 85-97.

[19] Varela AC, Santos IF. Dynamic coefficients of a tilting pad with active lubrication: Comparison between theoretical and experimental results, Journal of Tribology 2015; 137(3): 031704.

[20] Nicoletti R, Santos IF. Linear and Non-Linear Control Techniques Applied to Actively Lubricated Journal Bearings. Journal of Sound and Vibration 2003; 260(5): 927-947.

[21] Nicoletti R, Santos IF. Frequency response analysis of an actively lubricated rotor/tilting-pad bearing system. Journal of Engineering for Gas Turbines and Power 2005; 127(3): 638-645. 
[22] Nicoletti R, Santos IF. Control System Design for Flexible Rotors Supported by Actively Lubricated Bearings. Journal of Vibration and Control 2008; 14(3): 347-374.

[23] Santos IF, Scalabrin A. Control System Design for Active Lubrication With Theoretical and Experimental Examples. Journal of Engineering for Gas Turbines and Power 2003; 125(1): 75-80.

[24] Santos IF, Nicoletti R, Scalabrin A. Feasibility of Applying Active Lubrication to Reduce Vibration in Industrial Compressors. Journal of engineering for Gas Turbines and Power 2004; 126(4): 848-854.

[25] Salazar JG, Santos IF. Exploring integral controllers in activelylubricated tilting-pad journal bearings. Proc IMechE Part J: J Engineering Tribology 2015; 229(7): 835-848.

[26] Salazar JG, Santos IF. Feedback-controlled lubrication for reducing the lateral vibration of flexible rotors supported by tilting-pad journal bearings.Proc IMechE Part J: J Engineering Tribology 2015; 229(10): 12641275 .

[27] Nicholas J, Gunter EJ, Barrett LE. The influence of tilting pad bearing characteristics on the stability of high-speed rotor-bearing systems. In: Topics in Fluid Film Bearing and Rotor Bearing System Design and Optimization 1978; 55-78.

[28] Flack R, Zuck C. Experiments on the stability of two flexible rotors in tilting pad bearings. Tribology Transactions 1988; 31(2): 251-257.

[29] Taylor AG, Craggs A. The effect of damping on the stability of a finite element model of a flexible non-axisymmetric rotor on tilting pad bearings. Journal of sound and vibration 1995; 185(5): 809-825.

[30] Cloud CH, Maslen EH, Barrett LE. Rotor stability estimation with competing tilting pad bearing models. Mechanical Systems and Signal Processing 2012; 29: 90-106.

[31] Dimond T, Younan A, Allaire P. The Effect of Tilting Pad Journal Bearing Dynamic Models on the Linear Stability Analysis of an 8-Stage Compressor. ASME Journal of Engineering for Gas Turbines and Power $2012 ; 134(5): 052503$. 
[32] Wang W, Li Q, He F, Allaire P. Numerical and experimental stability investigation of a flexible rotor on two different tilting pad bearing configurations. International Journal of Rotating Machinery 2014; (2014): 697925 .

[33] Cerda A, Santos IF. Stability Analysis of an Industrial Gas Compressor supported by Tilting-Pad Journal Bearings under Different Lubrication Regimes. Journal of Engineering for Gas Turbines and Power, ASME Trans. 2012; 134(2): 022504.

[34] Santos IF. Theoretical and Experimental Identification on the Stiffness and Damping Coefficients of Active-Tilting Pad Journal Bearings. In: M. Friswell, M. J.E. (Eds.), Identification in Engineering Systems, The Cromwell Press Ltd., Swansea,Great Britain, 1996, 325-334.

[35] Santos IF, Nicoletti R. Influence of orifice distribution on the thermal and static properties of hybridly lubricated bearings. International Journal of Solids and Structures 2001; 38(10): 2069-2081.

[36] Haugaard AM, Santos IF. Multi-orifice Active Tilting-Pad Journal Bearings-Harnessing of Synergetic Coupling Effects. Tribology International 2010; 43(8): 1374-1391.

[37] Haugaard AM, Santos IF. Stability of Multi Orifice Active Tilting-Pad Journal Bearings, Tribology International 2010; 43(9): 1742-1750.

[38] Salazar JG, Santos IF. On the Controllability and Observability of Actively-Lubricated Journal Bearings with Pads Featuring Different Nozzle-Pivot Configurations. Journal of Tribology, ASME transactions 2017; 139(3): 031702.

[39] Merritt H. Hydraulic Control Systems. Wiley and Sons, Inc., 1967.

[40] Salazar JG, Santos IF. Experimental identification of dynamic coefficients of lightly-loaded tilting-pad bearings with active lubrication. Proc IMechE Part J: J Engineering Tribology. February 26, 2016. doi: $10.1177 / 1350650116635926$.

[41] Varela AC, Santos IF. Tilting-pad journal bearings with active lubrication applied as calibrated shakers: Theory and experiment. Journal of Vibration and Acoustics 2014; 136(6): 061010. 
[42] Santos IF. Mechatronics applied to machine elements with focus on active control of bearing, shaft and blade dynamics. Technical University of Denmark. Department of Mechanical Engineering, 2010.

[43] Lund J. Spring and Damping for the Tilting-Pad Journal Bearings. ASLE Transactions 1964; 7(4): 342-352.

[44] Lund J, Thomsen K. A calculation method and data for the dynamic coefficients of oil-lubricated journal bearings, in: Topics in fluid film bearing and rotor bearing system design and optimization, ASME, New York, 1978, 1-28.

[45] Springer H. Dynamic characteristics of sliding bearings with movable segments. VDI-Berichte 1980; 381: 177-184.

[46] Allaire P, Parsell J, Barrett L. A Pad Perturbation Method for the Dynamic Coefficients of Tilting-Pad Journal Bearings. Wear 1981; 72(1): 29-44.

[47] Earles L, Palazzolo A, Armentrout R. A Finite Element Approach to Pad Flexibility Effects in Tilting Pad Journal Bearings: Part I - Single Pad Analysis. ASME Journal of Tribology 1990; 112(2) : 169-176.

[48] Earles L, Palazzolo A, Armentrout R. A Finite Element Approach to Pad Flexibility Effects in Tilting Pad Journal Bearings: Part II - Assembled Bearing and System Analysis. ASME Journal of Tribology 1990; 112(2): 178-182.

[49] Fillon M, Bligoud JC, Frêne J. Experimental Study of Tilting-Pad Journal Bearings - Comparison with Theoretical Thermoelastohydrodynamic Results. ASME Journal of Tribology 1992; 114: 579-588.

[50] Knight J, Barrett L. Analysis of Tilting Pad Journal Bearings with Heat Transfer Effects. ASME Journal of Tribology 1988; 110: 128-133.

[51] Dimond T, Younan A ,Allaire P, Comparison of Tilting-Pad Journal Bearing Dynamic Full Coefficients and Reduced Order Models using Modal Analysis. ASME Journal of Vibration and Acoustics 2010; 132: 13-43. 
[52] Nelson H, McVaugh J. The Dynamics of Rotor-Bearing Systems Using Finite Element. J. Eng. Ind 1976; 98: 593-600.

[53] Burrows C, Sayed-Esfahani R, Stanway R. A comparison of multifrequency techniques for measuring the dynamics of squeeze-film bearings. Journal of Lubrication Technology 1981; 103(1): 137-143. 


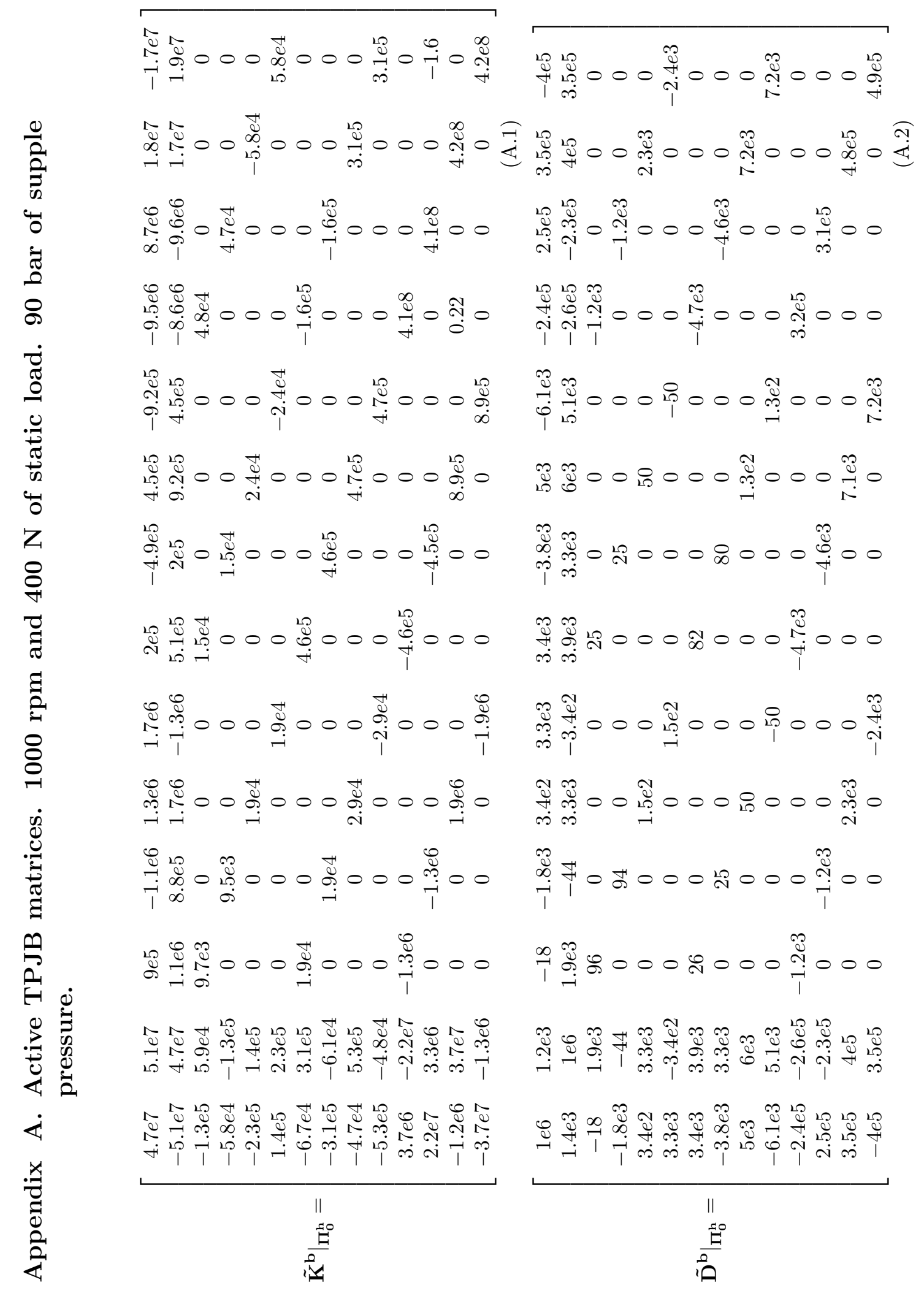




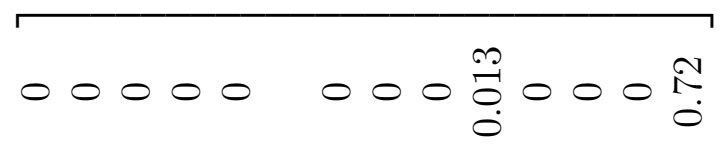

$$
\begin{aligned}
& 00000000 \stackrel{m}{0}_{0}^{\infty} 00 \stackrel{0}{i}_{0}
\end{aligned}
$$

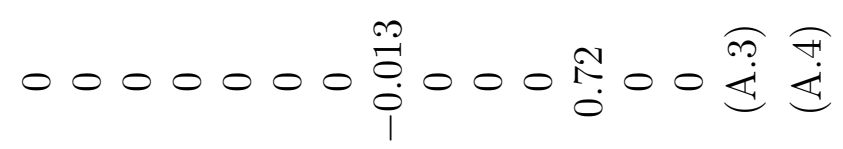

$$
\begin{aligned}
& 000000 \stackrel{0}{0}_{0}^{\infty} 000 \stackrel{0}{0} 000
\end{aligned}
$$

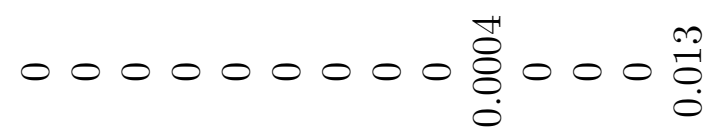

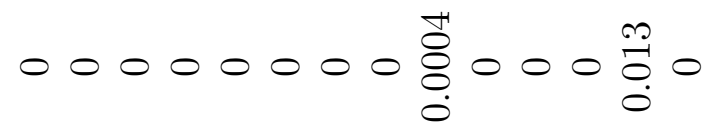

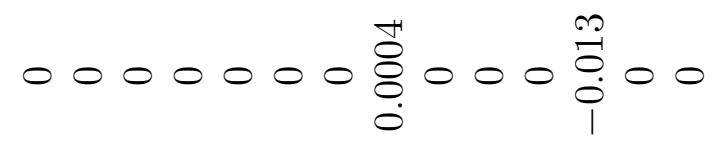

$$
\begin{aligned}
& 000000 \stackrel{⿱}{0} 000 \stackrel{\leftrightarrow}{0}_{0}^{\infty} 000
\end{aligned}
$$

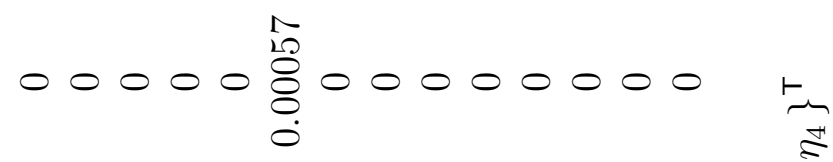

$$
\begin{aligned}
& \text { ก } \\
& 0000 \overbrace{0}^{0} 000000000 \\
& 000 \stackrel{D}{2}_{\substack{0 \\
0}}^{R} 000000000 \\
& 00 \stackrel{1}{8}_{0}^{1} 00000000000 \\
& 00000000000000 \\
& 00000000000000 \\
& \| \\
& \text { 点 }
\end{aligned}
$$

